ARTICLE

Received 23 Jun 2015 | Accepted 15 Oct 2015 | Published 18 Nov $2015 \quad$ DOl: 10.1038/ncomms9911 OPEN

\title{
Chemical basis for the recognition of trimethyllysine by epigenetic reader proteins
}

Jos J.A.G. Kamps ${ }^{1, \star}$, Jiaxin Huang ${ }^{2, \star}$, Jordi Poater ${ }^{3, \star}$, Chao Xu ${ }^{4}$, Bas J.G.E. Pieters ${ }^{1}$, Aiping Dong ${ }^{4}$, Jinrong Min ${ }^{4}$, Woody Sherman ${ }^{5}$, Thijs Beuming ${ }^{5}$, F. Matthias Bickelhaupt ${ }^{1,3}$, Haitao Li $^{2} \&$ Jasmin Mecinović ${ }^{1}$

A large number of structurally diverse epigenetic reader proteins specifically recognize methylated lysine residues on histone proteins. Here we describe comparative thermodynamic, structural and computational studies on recognition of the positively charged natural trimethyllysine and its neutral analogues by reader proteins. This work provides experimental and theoretical evidence that reader proteins predominantly recognize trimethyllysine via a combination of favourable cation- $\pi$ interactions and the release of the high-energy water molecules that occupy the aromatic cage of reader proteins on the association with the trimethyllysine side chain. These results have implications in rational drug design by specifically targeting the aromatic cage of readers of trimethyllysine.

\footnotetext{
${ }^{1}$ Institute for Molecules and Materials, Radboud University, Heyendaalseweg 135, 6525 AJNijmegen, The Netherlands. ${ }^{2}$ Department of Basic Medical Sciences, Center for Structural Biology, School of Medicine, Tsinghua University, Beijing 100084, China. ${ }^{3}$ Department of Theoretical Chemistry and Amsterdam Center for Multiscale Modeling, VU University, De Boelelaan 1083, 1081 HV Amsterdam, The Netherlands. ${ }^{4}$ Structural Genomics Consortium, University of Toronto, 101 College Street, Toronto, Ontario, Canada M5G 1L7. ${ }^{5}$ Schrödinger, Inc., 120 West 45th Street, New York, New York 10036 USA.

* These authors contributed equally to this work. Correspondence and requests for materials should be addressed to J.M. (email: j.mecinovic@science.ru.nl).
} 
T he positioning and chemical diversity of post-translational modifications on histone proteins orchestrate the structure and function of the eukaryotic chromatin ${ }^{1-3}$. One such modification is lysine methylation, which is associated both with gene activation and repression, depending on the type of histone and details of the sequence site ${ }^{4}$. The methylation of lysine residues of histone proteins is a dynamic process that is regulated by SAM-dependent histone lysine methyltransferases, FAD- or $\mathrm{Fe}(\mathrm{II}) / 2 \mathrm{OG}$-dependent histone demethylases, and reader proteins (also known as effector proteins) that specifically recognize post-translationally modified lysines in histones and affect the downstream cellular processes ${ }^{5-7}$. Enzymatic lysine methylation can lead to the formation of monomethyllysine (Kmel), dimethyllysine (Kme2) and trimethyllysine (Kme3), with each methylation mark being specifically recognized by different classes of the interacting reader proteins ${ }^{8}$. Lower methylation states Kme1 and Kme2 are specifically read by 53BP1 tandem tudor domains, L3MBTL1 MBT repeats, G9a ankyrin repeats and ORC1 BAH domain, primarily via the cavity-insertion binding mode ${ }^{9-13}$. The constitution of the Kme1/Kme2 recognition site enables the specificity in two ways: the methylammonium group forms the energetically favourable hydrogen bonding and electrostatic interactions with the negatively charged aspartate or glutamate, allowing the methyl group to position towards the aromatic residues, and the narrow binding pocket sterically prevents the access of the bulkier Kme3. The highest methylation state Kme3 is specifically recognized by a structurally diverse class of reader proteins, including plant homeodomain (PHD) zinc fingers, WD40 repeats and members of the Royal superfamily (tudor domain, chromodomain and PWWP domain), in the surface-groove binding mode ${ }^{8,10}$. For the Kme 3 reading modules, binding studies of histone peptides showed that binding affinities typically follow the trend $\mathrm{Kme} 3>\mathrm{Kme} 2>\mathrm{Kmel}>\mathrm{K}$ (ref. 14). With the exception of ATRX ADD domain, most characterized reader proteins specifically recognize Kme3 through an aromatic cage that consists of 1-4 aromatic amino acids (Phe, Tyr and Trp) and/or one methionine ${ }^{15}$. Aromatic cages of several reader modules also contain negatively charged Asp or Glu residues. The positioning of the quaternary ammonium (Kme3) group inside the aromatic cage, as demonstrated by structural determination of several reader-Kme3 complexes, suggests that the specific readout process is primarily driven by cation- $\pi$ interactions, although charge-independent interactions may also contribute to the overall binding $8,16-18$. Herein we report clear experimental and computational support for the chemical basis for the recognition of Kme3-containing histones by reader proteins. Our study reveals that the association between trimethyllysine and the aromatic cage of reader proteins is driven by energetically favourable cation $-\pi$ interactions between the positively charged trimethyllysine and the electron-rich aromatic cage, and the trimethyllysine-mediated release of non-optimally structured water molecules that occupy the aromatic cages of reader proteins.

\section{Results}

Physical-organic chemistry approach. Specific favourable binding of the positively charged side chain of Kme3 to the aromatic cage of reader proteins could, in principle, be a result of (i) favourable solute-solute interactions (cation- $\pi$ and $\mathrm{CH}-\pi$ interactions), (ii) partial desolvation of the Kme3 side chain of histone tails (via the hydrophobic effect), and/or (iii) desolvation of the aromatic cage of reader proteins. To elucidate the underlying chemical basis for the recognition of natural Kme3 by reader proteins, we have carried out detailed comparative studies for binding of 10-mer histone peptides that contain the positively charged Kme3, its neutral carba analogue $\mathrm{Cme}$, and the glycine residue that lacks the entire side chain at the fourth position of histone 3 (that is, H3K4me3, H3C4me3 and H3G4; Fig. 1a). We have chosen the simplest uncharged $\mathrm{Cme} 3$ analogue to directly probe the involvement of the proposed cation $-\pi$ interactions in reader-histone associations, because it has virtually the same size, shape and polarizability as the positively charged Kme3, but lacks the presence of the fixed positive charge ${ }^{16}$. Values for volumes of Kme3 $\left(160.2 \AA^{3}\right)$ and Cme3 $\left(158.2 \AA^{3}\right)$ indicate that, in the case that the binding mode is the same for both side chains, they should displace the same amount of water molecules from the protein site on binding. We have chosen the 10-mer H3G4 peptide to explore the importance of the entire side chain of Kme3 on association with reader proteins. The Kme3/Cme3 $\rightarrow G$ substitution directly probes the significance of the potential displacement of water molecules that are localized inside the aromatic cage of reader proteins.

Thermodynamic analyses of reader-histone association. We use isothermal titration calorimetry (ITC) to obtain full thermodynamic descriptions for binding of $\mathrm{H} 3 \mathrm{~K} 4 \mathrm{me} 3, \mathrm{H} 3 \mathrm{C} 4 \mathrm{me} 3$ and H3G4 peptides to five representative reader proteins that specifically recognize $\mathrm{H} 3 \mathrm{~K} 4 \mathrm{me} 3$ (the PHD zinc fingers of JARID1A, BPTF, TAF3 and the tudor domains of the Royal family of SGF29 and JMJD2A) (Table 1 and Fig. $1 b, c)^{19-23}$. The five reader pockets are different in the aromatic cage composition and architecture, which allows us to examine the effect of individual constitution of the aromatic cage on binding differences. Comparative ITC experiments for the associations of $\mathrm{H} 3 \mathrm{~K} 4 \mathrm{me} 3$ and $\mathrm{H} 3 \mathrm{C} 4 \mathrm{me} 3$ showed that: (i) the positively charged H3K4me3 binds 2-33-fold stronger than the neutral H3C 4 me 3 to 4 out of 5 reader proteins that contain Trp as part of the aromatic cage (JARID1A, TAF3, BPTF and JMJD2A; Table 1); (ii) association of the Kme3 side chain with the aromatic cage is on average about $4.3 \mathrm{kcal} \mathrm{mol}^{-1}$ more favourable in enthalpy than the association of the neutral $\mathrm{Cme} 3$ group to the same cage; and (iii) association of the Kme3 side chain is about $3.1 \mathrm{kcal} \mathrm{mol}^{-1}$ less favourable in entropy than the association of the Cme3 group to the same aromatic pocket. Collectively, these data provide evidence for the presence of the favourable cation $-\pi$ interactions in the natural readout process, as exemplified by the enthalpy-driven association of the naturally occurring Kme3 with the electron-rich aromatic cage of reader proteins. In contrast to other readers that contain at least one Trp residue, H3K4me3 and H3C4me3 bound to the tandem tudor domain of SGF29 with virtually indistinguishable thermodynamics of associations, indicating the lack (or at least a minor contribution) of cation $-\pi$ interactions in the association of Kme3 by the Tyr/Phecontaining half aromatic cage of SGF29 (Table 1). This result is consistent with the well-established observation that the strength of cation- $\pi$ interactions depends on the nature of the aromatic ring $^{24-32}$. Studies on the related protein systems showed that Trp forms significantly stronger cation $-\pi$ interactions with quaternary ammonium ions than do Phe or Tyr residues ${ }^{24,25}$. For SGF29, the electrostatic interactions between Kme3 and D266, and between the positively charged $\alpha$-amino group of $\mathrm{Al}$ and the H3A1 binding pocket importantly contribute to the overall binding affinity of H3K4me3 (refs 22,33).

Negative values of the heat capacities $\left(\Delta \mathrm{C}_{\mathrm{p}}\right)$ for binding of $\mathrm{H} 3 \mathrm{~K} 4 \mathrm{me} 3$ and $\mathrm{H} 3 \mathrm{C} 4 \mathrm{me} 3$ to reader proteins were also determined by ITC. In all the cases examined, we observed more negative values for $\mathrm{H} 3 \mathrm{C} 4 \mathrm{me} 3$ than for $\mathrm{H} 3 \mathrm{~K} 4 \mathrm{me} 3$ : JARID1AH3K4me3 $-162 \pm 4 \mathrm{cal} \mathrm{mol}^{-1} \mathrm{~K}^{-1}$, JARID1A-H3C4me3 $-182 \pm 3 \mathrm{cal} \mathrm{mol}^{-1} \mathrm{~K}^{-1}$; TAF3-H3K4me3 $-142 \pm 7 \mathrm{cal} \mathrm{mol}^{-1} \mathrm{~K}^{-1}$, TAF3-H3C4me3 $-171 \pm 8 \mathrm{cal} \mathrm{mol}^{-1} \mathrm{~K}^{-1}$; $\quad$ BPTF-H3K4me3 
$-103 \pm 6 \mathrm{cal} \mathrm{mol}^{-1} \mathrm{~K}^{-1}$, BPTF-H3C4me3 -145 $\pm 7 \mathrm{cal} \mathrm{mol}^{-1} \mathrm{~K}^{-1}$ (Supplementary Fig. 1). These results are in agreement with the involvement of the classical hydrophobic interactions for binding of $\mathrm{H} 3 \mathrm{C} 4 \mathrm{me} 3$ to the aromatic cage of reader proteins; this suggests that entropy-driven (partial) desolvation of the
Cme3 side chain contributes favourably to the binding affinity $^{34-37}$. Binding of the uncharged Cme3 to the aromatic cage can additionally be attributed to the energetically favourable $\mathrm{CH}-\pi$ hydrogen bonding with a strong polarization component $\mathrm{c}^{38,39}$.

a<smiles>[Z6]C(=O)[C@H](CCCC[N+](C)(C)C)NC</smiles>

H3K4me3<smiles>[Z]C(=O)[C@H](CCCCC(C)(C)C)NC(C)(C)C</smiles>

$\mathrm{H} 3 \mathrm{C} 4 \mathrm{me} 3$<smiles>CC(C)(C)NCC(=O)C(C)(C)C</smiles>

H3G4 b

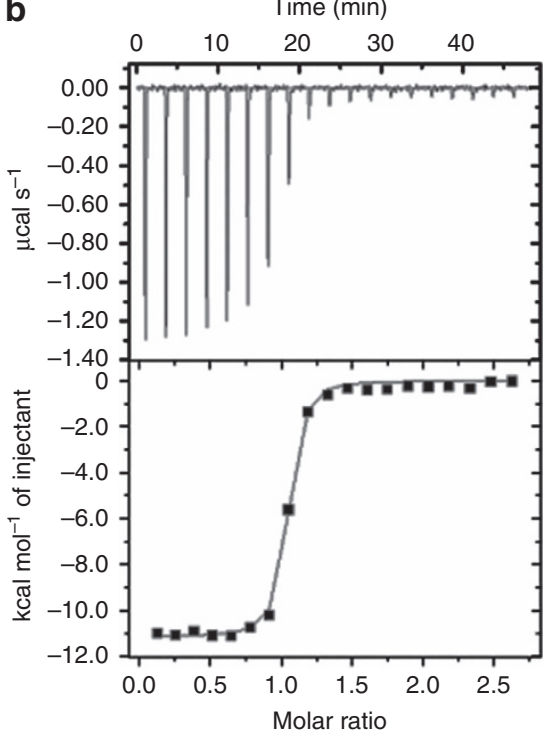

C

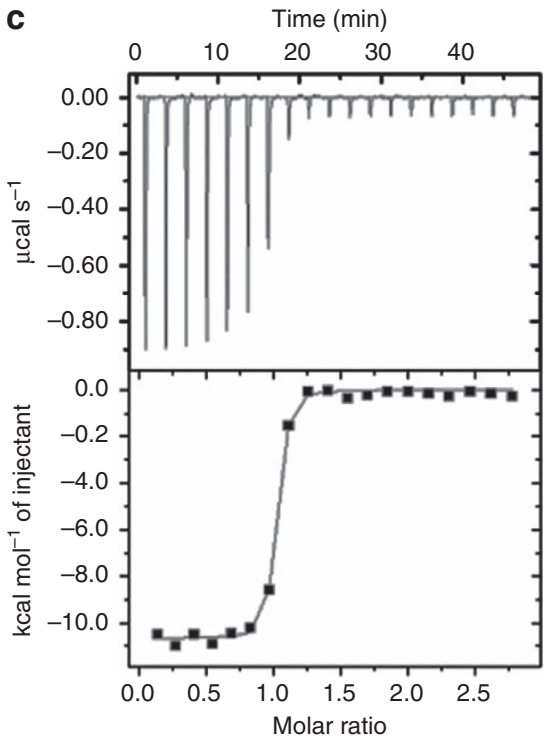

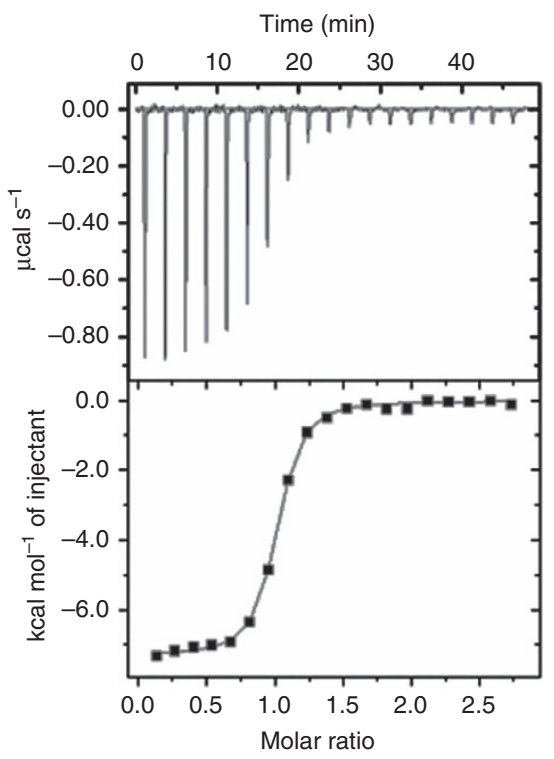

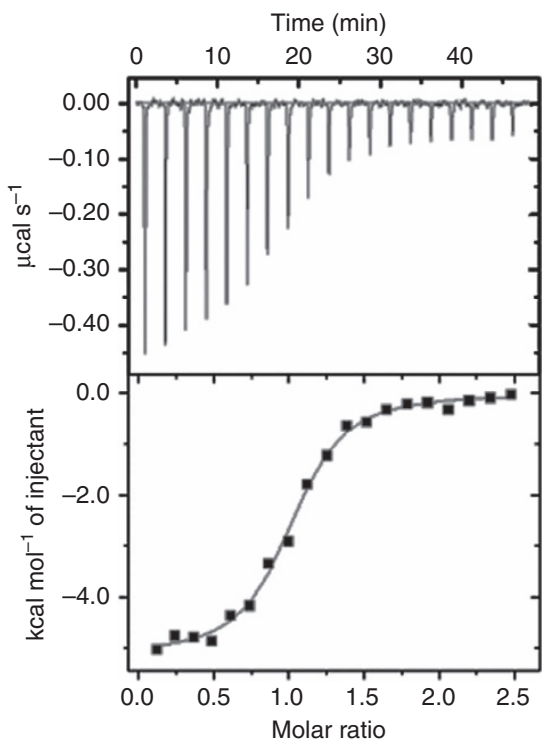

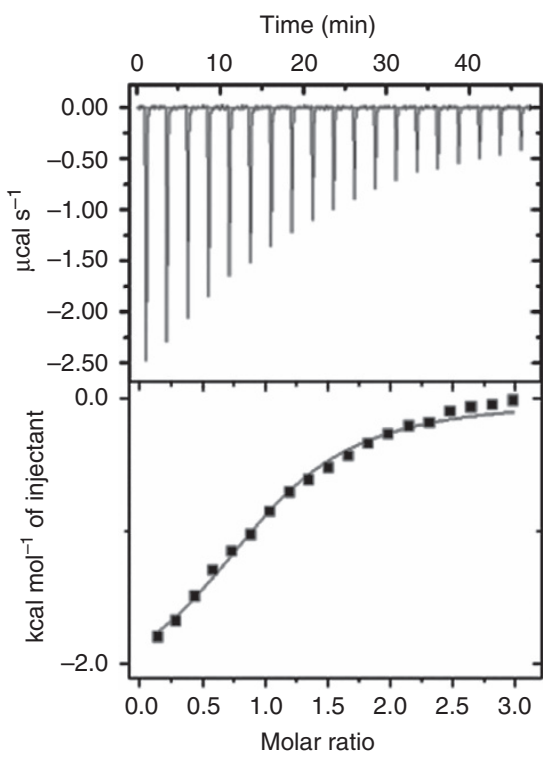

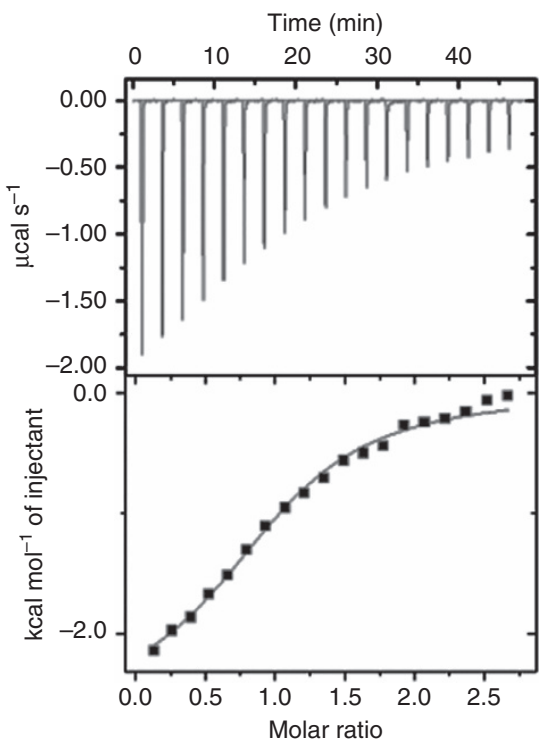

Figure 1 | Thermodynamic analyses of binding. (a) Structures of the positively charged Kme3 and neutral Cme3 and G analogues; (b) ITC curves of 10-mer H3K4me3, H3C4me3 and H3G4 histone peptides binding to the JARID1A PHD3 domain; (c) ITC curves of 10-mer H3K4me3, H3C4me3 and H3G4 histone peptides binding to the TAF3 PHD domain. 
We further examined the contribution of the entire Kme3 side chain to the overall binding associations with the aromatic cage of reader proteins. ITC data showed that binding of 10-mer H3G4 to all five reader proteins was dramatically reduced ( $>500$-fold) when compared with binding of the H3K4me3 counterpart, highlighting the importance of the entire side chain in the complexation process. More detailed thermodynamic analyses were only possible with JARID1A and TAF3, because both proteins bind to the reference $\mathrm{H} 3 \mathrm{~K} 4 \mathrm{me} 3$ peptide with $K_{\mathrm{d}}$ values in submicromolar range and the H3G4 peptide had sufficient residual affinity for ITC characterization (Fig. 1b,c): JARID1A-H3G4 $\left(K_{\mathrm{d}}=88 \mu \mathrm{M}, \Delta G^{\circ}=-5.5 \mathrm{kcal} \mathrm{mol}^{-1}, \Delta H^{\circ}=\right.$ $\left.-2.1 \mathrm{kcal} \mathrm{mol}^{-1}, \quad-\mathrm{T} \Delta S^{\circ}=-3.4 \mathrm{kcal} \mathrm{mol}^{-1}\right)$ and TAF3-H3G4 $\left(K_{\mathrm{d}}=36 \mu \mathrm{M}, \Delta G^{\circ}=-6.1 \mathrm{kcal} \mathrm{mol}^{-1}, \Delta H^{\circ}=-2.5 \mathrm{kcal} \mathrm{mol}^{-1}\right.$, $-\mathrm{T} \Delta S^{\circ}=-3.6 \mathrm{kcal} \mathrm{mol}^{-1}$ ). Overall, thermodynamic data revealed that (i) binding of the entire side chain of the Kme3 contributes about $-4 \mathrm{kcal} \mathrm{mol}^{-1}$ (that is, about $40 \%$ ) to the overall Gibbs binding free energy $\left(\Delta G^{\circ}\right)$; (ii) favourable enthalpy provides a dominant contribution $\left(\sim-8.5 \mathrm{kcal} \mathrm{mol}^{-1}\right)$ to the binding of the entire Kme3 side chain to the aromatic cage; and (iii) entropy of binding becomes more favourable $\left(-\mathrm{T} \Delta \Delta S^{\circ}=-4.5 \mathrm{kcal} \mathrm{mol}^{-1}\right)$ for $\mathrm{H} 3 \mathrm{G} 4$ relative to $\mathrm{H} 3 \mathrm{~K} 4 \mathrm{me}$. In addition to thermodynamics results on $\mathrm{H} 3 \mathrm{C} 4 \mathrm{me} 3$, these results indicate that favourable cation $-\pi$ interactions are not solely responsible for strong binding affinity of $\mathrm{H} 3 \mathrm{~K} 4 \mathrm{me} 3$, but that other types of solute-solute interactions and reader/histone desolvation could also play an important role in the specific readout of Kme3.

Structural determination of reader-H3C4me3 complexes. Having shown that the removal of the positive charge in $\mathrm{Kme} 3$ (as in the neutral $\mathrm{H} 3 \mathrm{C} 4 \mathrm{me} 3$ ) resulted in reduced binding affinity for most reader proteins due to less favourable enthalpy of binding, we aimed to rationalize these results in conjunction with structural analyses for reader-H3C4me3 complexes. We solved three X-ray crystal structures for complexes with JARID1A, TAF3 and SGF29 at 1.6-2.8 $\AA$ resolution (Fig. 2 and Table 2). All three reader-H3C4me3 structures clearly illustrated that the uncharged side chain of $\mathrm{C} 4 \mathrm{me} 3$ is positioned well inside the aromatic cages of JARID1A, TAF3 and SGF29, virtually in the same binding mode as the positively charged Kme3 (Fig. $2 \mathrm{a}-\mathrm{c}$ ). The calculated average values of the root-mean-squared deviation for binding of 'Cme3' and 'Kme3'-aromatic cage pairs were: $0.124 \AA$ for JARID1A, $0.261 \AA$ for TAF3 and $0.108 \AA$ for SGF29, respectively, suggesting essentially the same complexation mode engaging in aromatic pocket residues upon binding of neutral C4me3 (Fig. 2d-f). In all three complexes, the carba histone peptide binds to an electrostatically negative surface with the long C4me3 side chain positioned in a surface groove formed by the caging residues (Fig. 2g-i and Supplementary Fig. 2). On the formation of the JARID1A-H3C4me3 complex, the buried solvent accessible surface area (SASA) of C4me3 (hydrogen atoms added) is $160.6 \AA^{2}$, which accounts for $38.8 \%$ of the total SASA of C4me3, as compared with Kme3 binding to JARID1A with a buried SASA of $163.8 \AA^{2}$, which equals $39.5 \%$ of total SASA. Similar features have also been observed for binding of $\mathrm{H} 3 \mathrm{C} 4 \mathrm{me} 3$ and $\mathrm{H} 3 \mathrm{~K} 4 \mathrm{me} 3$ to TAF3 with $48.3 \%$ buried SASA for $\mathrm{H} 3 \mathrm{C} 4 \mathrm{me} 3$ and $50.1 \%$ buried SASA for H3K4me3, and to SGF29 with 48.6 and $47.3 \%$ buried SASA for $\mathrm{H} 3 \mathrm{C} 4 \mathrm{me} 3$ and $\mathrm{H} 3 \mathrm{~K} 4 \mathrm{me} 3$, respectively.

Computational analyses in the gas and aqueous phase. Our aim is to elucidate the nature and selectivity of the non-covalent interactions between the aromatic cage that consists of two tryptophan residues of JARID1A (hereafter designated as TRP2 fragment) and the Kme3 versus $\mathrm{Cme} 3$ side chain of the histone peptide. To this end, we have quantum chemically characterized the energetics and bonding mechanism in two model complexes, using dispersion-corrected density functional theory at BLYP-D3BJ/TZ2P and COSMO for simulating aqueous solution, as implemented in the Amsterdam Density Functional (ADF) program ${ }^{40,41}$. The model complexes consist of those moieties of the JARID1A-H3K4me3 and JARID1A-H3C4me3 X-ray structures that give rise to the intermolecular interaction in the full reader-histone complexes (Supplementary Table 1). The chosen subsystems were terminated with one hydrogen at $\mathrm{C}_{\beta}$ of the Kme3 or Cme3 side chain and one hydrogen at each $\mathrm{C}_{\beta}$ of the TRP2 fragment. Thus, Kme3 and Cme3 fragments are fully optimized, both as isolated molecules and as molecular fragments in the complex with TRP2. To simulate the structural rigidity that is imposed by the protein backbone in the full protein system, the TRP2 fragment is kept frozen to the X-ray structure, both as a separate fragment and in the complexes. Geometries of the optimized model systems differ only very slightly from the X-ray structures.

Our computations show that, in line with experimental data, there is an energetic preference of $\sim 2 \mathrm{kcal} \mathrm{mol}^{-1}$ for the JARID1A-Kme3 over the JARID1A-Cme3 model complex with bond energies $\Delta E(\mathrm{aq})$ of -10.2 and $-8.4 \mathrm{kcal} \mathrm{mol}^{-1}$, respectively (Table 3). The geometries of the two model complexes are similar, but $\mathrm{NMe}_{3}^{+}$in the JARID1A-Kme3 model is somewhat closer to the TRP2 tryptophan cage than $\mathrm{CMe}_{3}$ in the JARID1A-Cme3 model. The closest $\mathrm{H}-\mathrm{C}$ distances between an $\mathrm{NMe}_{3}^{+} \mathrm{H}$ atom and a $\mathrm{C}$ atom of a tryptophan in the JARID1A-Kme3 model is $2.78 \AA$, while the same $\mathrm{H}$ atom is $3.38 \AA$ away from the closest $\mathrm{C}$ atom of the other tryptophan. For comparison, the corresponding $\mathrm{H}-\mathrm{C}$ distances in the JARID1A-Cme 3 model are 3.16 and $3.15 \AA$ (Table 3 and Supplementary Fig. 3). A characteristic difference in geometries comes from the conformation of Kme3 and $\mathrm{Cme} 3$. In the former, the chain of four carbon atoms has a zigzag conformation whereas, in the latter, this chain is $U$ shaped.

Our bonding analyses reveal that the bond energies $\Delta E(\mathrm{aq})$ associated with the molecular recognition processes of Kme3

Table 1 | Thermodynamic parameters for the associations of 10-mer H3K4me3 and H3C4me3 peptides (ART(Kme3/Cme3)QTARKS) to five reader proteins*.

\begin{tabular}{|c|c|c|c|c|c|c|c|c|}
\hline & \multicolumn{4}{|c|}{ H3K4me3 } & \multicolumn{4}{|c|}{ H3C4me3 } \\
\hline & $\begin{array}{c}K_{\mathrm{d}} \\
(\mu \mathrm{M})\end{array}$ & $\begin{array}{c}\Delta G^{\circ} \\
\left(\mathrm{kcal} \mathrm{mol}^{-1}\right) \\
\end{array}$ & $\begin{array}{c}\Delta H^{\circ} \\
\left(\mathrm{kcal} \mathrm{mol}^{-1}\right) \\
\end{array}$ & $\begin{array}{c}-\mathrm{T} \Delta S^{\circ} \\
\left(\mathrm{kcal} \mathrm{mol}{ }^{-1}\right) \\
\end{array}$ & $\begin{array}{c}K_{\mathrm{d}} \\
(\mu \mathrm{M})\end{array}$ & $\begin{array}{c}\Delta G^{\circ} \\
\left(\mathrm{kcal} \mathrm{mol}^{-1}\right) \\
\end{array}$ & $\begin{array}{c}\Delta H^{\circ} \\
\left(\mathrm{kcal} \mathrm{mol}^{-1}\right) \\
\end{array}$ & $\begin{array}{c}-\mathrm{T} \Delta S^{\circ} \\
\left.\text { (kcal mol }^{-1}\right) \\
\end{array}$ \\
\hline JARID1A & 0.094 & $-9.6 \pm 0.1$ & $-11.0 \pm 0.1$ & $1.4 \pm 0.1$ & 0.34 & $-8.8 \pm 0.1$ & $-7.4 \pm 0.1$ & $-1.4 \pm 0.1$ \\
\hline BPTF & 0.49 & $-8.6 \pm 0.1$ & $-13.1 \pm 0.1$ & $4.5 \pm 0.1$ & 0.76 & $-8.3 \pm 0.1$ & $-10.0 \pm 0.2$ & $1.7 \pm 0.2$ \\
\hline SGF29 & 1.7 & $-7.9 \pm 0.1$ & $-7.7 \pm 0.1$ & $-0.2 \pm 0.1$ & 1.4 & $-8.0 \pm 0.1$ & $-7.9 \pm 0.1$ & $-0.1 \pm 0.1$ \\
\hline JMJD2A & 0.94 & $-8.2 \pm 0.1$ & $-13.1 \pm 0.2$ & $4.9 \pm 0.2$ & 16 & $-6.5 \pm 0.1$ & $-8.1 \pm 0.1$ & $1.6 \pm 0.1$ \\
\hline
\end{tabular}

*Values obtained from 5-7 repeated ITC experiments. The stoichiometry (histone peptide:reader protein, $n$ ) =0.95-1.05. 
a

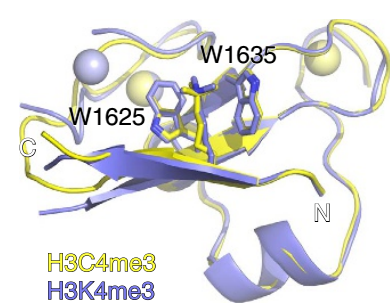

d

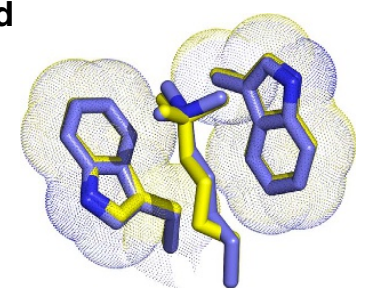

g

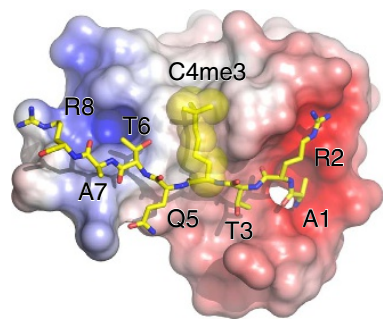

JARID1A b

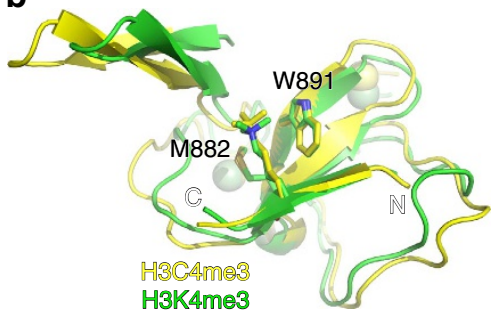

e

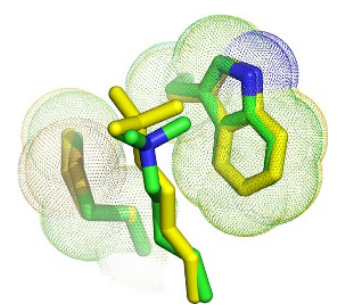

h

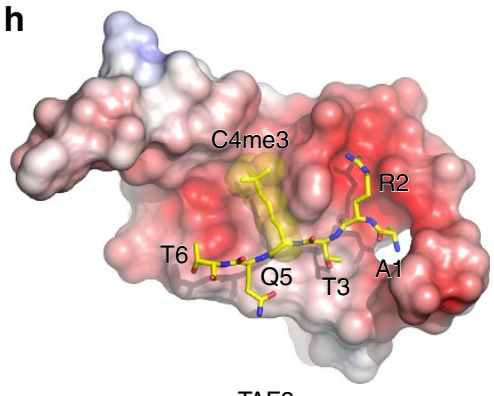

TAF3
C

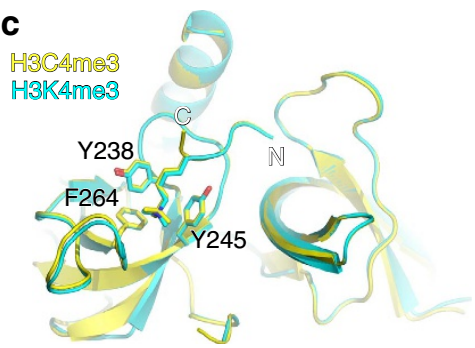

$\mathbf{f}$

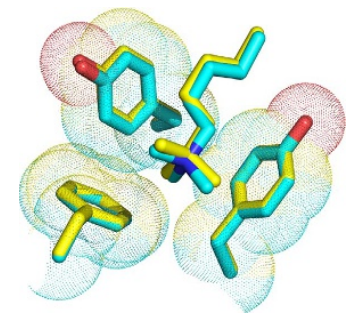

i

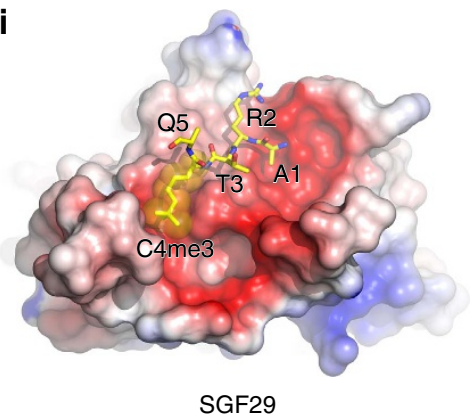

Figure 2 | Structural analyses of reader-histone interactions. Structural superimposition of H3C4me3 and H3K4me3-bound complexes of (a) the JARID1A PHD finger, (b) the TAF3 PHD finger and (c) the SGF29 tandem tudor domains. Overall structures are represented in ribbon view with key residues highlighted in stick. In all panels, the $\mathrm{H} 3 \mathrm{C} 4 \mathrm{me} 3$ peptides and their complexes are coloured yellow, and the H3K4me3 counterparts are colour coded blue for JARID1A, green for TAF3, and cyan for SGF29. Small spheres, zinc ions. Close-up view of the reader pockets are shown in d for JARID1A, $\mathbf{e}$ for TAF3 and $\mathbf{f}$ for SGF29. Van der Waals surfaces of caging residues are depicted as dots. Electrostatic surface view of H3C4me3 complexes of (g) JARID1A, (h) TAF3 and (i) SGF29. Red and blue colours indicate negative and positive electrostatic potential, respectively. H3 peptides are shown in stick mode with $\mathrm{C} 4 \mathrm{me} 3$ side chain overlaid with dotted van der Waals surfaces.

versus Cme3 in water are essentially identical with the corresponding instantaneous interaction energies $\Delta E_{\text {int }}(\mathrm{aq})$ of -10.3 and $-8.7 \mathrm{kcal} \mathrm{mol}^{-1}$, respectively. The reason is that complexation only very slightly changes the geometry of the Kme3 and Cme3 side chains as a result of which the associated deformation strain is negligible, that is, 0.1 and $0.3 \mathrm{kcal} \mathrm{mol}^{-1}$, respectively. The intrinsic preference for $\mathrm{Kme} 3$ over $\mathrm{Cme} 3$, that is, the interaction energy $\Delta E_{\text {int }}$ between the same structures but in the absence of the solvent, is even more in favour of the former with values of -27.6 and $-10.9 \mathrm{kcal} \mathrm{mol}^{-1}$, respectively (Table 3 ). The significantly stronger interaction energy of Kme3 is, however, strongly attenuated by the desolvation incurred on binding, which is significantly more unfavourable for Kme3. Thus, solvent effects destabilize the JARID1A-Kme3 complex by +17.3 , whereas the desolvation penalty in the JARID1A-Cme3 complex is only $+2.2 \mathrm{kcal} \mathrm{mol}^{-1}$. The reason for this large difference can be attributed to the removal of solvent (desolvation) around the positive charge of the Kme3 side chain ammonium group. Note that the stronger binding in JARID1A-Kme3 causes a reduction in the bond distances (see above), resulting in a computed Pauli repulsion energy between closed shells that is $+6.7 \mathrm{kcal} \mathrm{mol}^{-1}$ more repulsive for this more stable JARID1A-Kme3 complex.

The reason why the TRP2 unit interacts more favourably with Kme3 than with Cme3 becomes clear from our quantitative Kohn-Sham molecular orbital and energy decomposition analyses (EDA) of the interaction energy $\Delta E_{\text {int }}$ (Table 3$)^{42}$. Interestingly, although dispersion $\Delta E_{\text {disp }}$ is the largest contributor to the reader-histone interaction, it contributes only $4.4 \mathrm{kcal} \mathrm{mol}^{-1}$ to the $16.7 \mathrm{kcal} \mathrm{mol}^{-1}$ difference in $\Delta E_{\mathrm{int}}$ between JARID1A-Kme3 (-27.6 kcal mol-1) and JARID1ACme3 (-10.9 kcal mol ${ }^{-1}$; Table 3). Instead, the difference in stability between JARID1A-Kme3 and JARID1A-Cme3 mainly originates from the electrostatic $\left(\Delta \mathrm{V}_{\text {elstat }}\right)$ and orbital interaction $\left(\Delta \mathrm{E}_{\mathrm{oi}}\right)$ terms that favour the complex with Kme3 by 9.6 and $9.4 \mathrm{kcal} \mathrm{mol}^{-1}$, respectively.

The more attractive $\Delta V_{\text {elstat }}$ in case of Kme3 goes hand in hand with the significantly more positive charge on all atoms in the Kme3 ammonium, as inferred from our Voronoi deformation density (VDD) atomic charges ${ }^{43}$ (Fig. 3a). The nitrogen atom in Kme 3 carries a positive charge of +59 mili-a.u., which has to be compared with the negative charge of -40 mili-a.u. on the structurally analogous carbon atom in the overall neutral Cme3. Importantly, the hydrogen atoms of the trimethylammonium group of Kme3 are also significantly more positively charged than the corresponding ones of the tert-butyl group in Cme3. For example, the hydrogen atom closest to the reader's TRP2 fragment has an atomic charge of +84 and +29 mili-a.u. in Kme3 and Cme3, respectively (Fig. 3a).

Our Kohn-Sham molecular orbital analyses show that the enhanced orbital interactions $\Delta E_{\mathrm{oi}}$ in JARID1A-Kme3 result 
Table 2 | Data collection and refinement statistics.

\begin{tabular}{|c|c|c|c|}
\hline & JARID1A-H3C4me3 & TAF3-H3C4me3 & SGF29-H3C4me3 \\
\hline \multicolumn{4}{|l|}{ Data collection } \\
\hline Space group & 1432 & $\mathrm{P} 2_{1}$ & $\mathrm{P} 2{ }_{1} 2_{1} 2_{1}$ \\
\hline$a, b, c(\AA)$ & $108.9,108.9,108.9$ & $30.2,50.1,85.9$ & $50.1,65.2,105.2$ \\
\hline$\alpha, \beta, \gamma\left({ }^{\circ}\right)$ & $90,90,90$ & $90,90,90$ & $90,90,90$ \\
\hline Resolution $(\AA)$ & $50-2.8(2.87-2.80)^{\star}$ & $50-2.1(2.14-2.10)$ & $37.2-1.60(1.63-1.60)$ \\
\hline Completeness (\%) & $99.5(100)$ & $99.6(100)$ & $99.1(92.1)$ \\
\hline Redundancy & $17.1(14.4)$ & $3.7(3.7)$ & $6.8(6.6)$ \\
\hline \multicolumn{4}{|l|}{ Refinement } \\
\hline Resolution $(\AA)$ & $50-2.8$ & $32.6-2.1$ & $37.2-1.60$ \\
\hline No. reflections & 2,920 & 15,001 & 44,342 \\
\hline$R_{\text {work }} / R_{\text {free }}$ & $24.6 / 27.9$ & $22.2 / 28.0$ & $20.4 / 23.9$ \\
\hline \multicolumn{4}{|l|}{$B$-factors } \\
\hline Protein & 97.3 & 34.9 & 16.8 \\
\hline Ligand/ion & $80.3 / 86.9$ & $29.2 / 25.8$ & $19.7 / 34.6$ \\
\hline Water & & 37.7 & 25.9 \\
\hline \multicolumn{4}{|l|}{ R.m.s. deviations } \\
\hline Bond lengths $(\AA)$ & 0.003 & 0.014 & 0.009 \\
\hline Bond angles $\left({ }^{\circ}\right)$ & 0.698 & 1.58 & 1.384 \\
\hline
\end{tabular}

Table 3 | Quantum-chemical bonding analysis (energies in $\mathrm{kcal} \mathrm{mol}^{-1}$, distances in A) in TRP2-Kme3 and TRP2-Cme3 systems in aqueous solution*.

TRP2-Kme3

TRP2-Cme3

\begin{tabular}{lcc}
\hline$\Delta E(\mathrm{aq})$ & -10.2 & -8.4 \\
$\Delta E(\mathrm{aq})_{\text {strain }}$ & 0.1 & 0.3 \\
$\Delta E(\mathrm{aq})_{\text {int }}$ & -10.3 & -8.7 \\
$\Delta E(\mathrm{desolv})_{\text {int }}$ & +17.3 & +2.2 \\
$\Delta E_{\text {int }}$ & -27.6 & -10.9 \\
$\Delta E_{\text {Pauli }}$ & 20.8 & 14.1 \\
$\Delta V_{\text {elstat }}$ & -15.0 & -5.4 \\
$\Delta E_{\mathrm{oi}}$ & -13.0 & -3.6 \\
$\Delta E_{\text {disp }}$ & -20.4 & -16.0 \\
$\mathrm{~d}\left(\mathrm{H}_{\text {Me }}-\mathrm{C}_{\text {TRP-6MR }}\right)$ & 3.38 & 3.15 \\
$\mathrm{~d}\left(\mathrm{H}_{\mathrm{Me}}-\mathrm{C}_{\text {TRP-5MR }}\right)$ & 2.78 & 3.16
\end{tabular}

${ }^{*}$ Computed at BLYP-D3BJ/TZ2P with COSMO to simulate aqueous solution. Structural rigidity imposed by the protein backbone is simulated through constraint geometry optimizations. See also equations (1)-(3) in Methods section.

from both, stronger donor-acceptor orbital interactions and stronger polarization of the TRP2 fragment in the presence of the positively charged Kme3 than in the case of the neutral Cme3. Thus, the VDD analyses based on the two molecular fragments ${ }^{43}$ reveal a small but significant charge transfer of 0.04 electrons from the occupied $\pi$ fragment molecular orbitals (FMOs) on TRP2 to virtual $\sigma_{\mathrm{C}-\mathrm{N}}$ and $\sigma_{\mathrm{C}-\mathrm{H}}$ type FMOs on Kme3 whereas essentially no charge is transferred to FMOs on Cme3. One reason is the much lower energy of the acceptor orbitals in the positively charged Kme3 (Fig. 3b). Another reason is the better overlap between TRP $2 \pi$ orbitals and the acceptor orbitals of Kme3. This originates from the fact that the low-energy virtual orbitals of Kme3 are mainly localized on the positive trimethylammonium group through which Kme3 binds to TRP2, as can be seen in the realistic three-dimensional plots of relevant FMOs in Fig. 3b. The low-energy orbitals of Cme3 are more delocalized with less amplitude on the tert-butyl group close to TRP2. Consequently, in most cases TRP2-Kme3 overlaps are significantly larger than TRP2-Cme3 overlaps, as shown for the TRP2 highest occupied molecular orbital (HOMO) and HOMO-1 and the Kme3 or Cme3 lowest unoccupied molecular orbital (LUMO) and LUMO + 1 (Supplementary Table 2).

WaterMap calculations. Next, we ran WaterMap calculations for all five systems to evaluate the contribution of aromatic cage desolvation to the affinity of Kme 3 and $\mathrm{Cme} 3$ for reader proteins. WaterMap computes thermodynamic quantities (free energy, enthalpy and entropy) for simulated water molecules around a protein-binding site using explicit solvent molecular dynamics simulation and thermodynamic characterization. In short, regions of high solvent density from the molecular dynamic simulations are clustered into 'hydration sites', and thermodynamic quantities for these sites are calculated using inhomogeneous solvation theory ${ }^{44,45}$. For all five reader proteins, two to four high-energy hydration sites were identified within the aromatic cage (Fig. 4a-e). These hydration sites are displaced from the aromatic cage by both the Kme 3 and $\mathrm{Cme} 3$ side chain, but not by the H3G4 peptide. The total free energy contributed by desolvating the aromatic cage (determined as the difference in WaterMap scores between Kme3 and Gly) ranges from $4.3 \mathrm{kcal} \mathrm{mol}^{-1}$ for JARID1A to $8.7 \mathrm{kcal} \mathrm{mol}^{-1}$ for SGF29. Depending on the composition of the cage, this free energy reward can be both entropically and enthalpically driven (Fig. $4 \mathrm{f}$ and Supplementary Figs 4 and 5). For example, both TAF3 and JMJD2A contain an Asp residue that can form hydrogen bonds with the binding site water molecules, resulting in more 
a
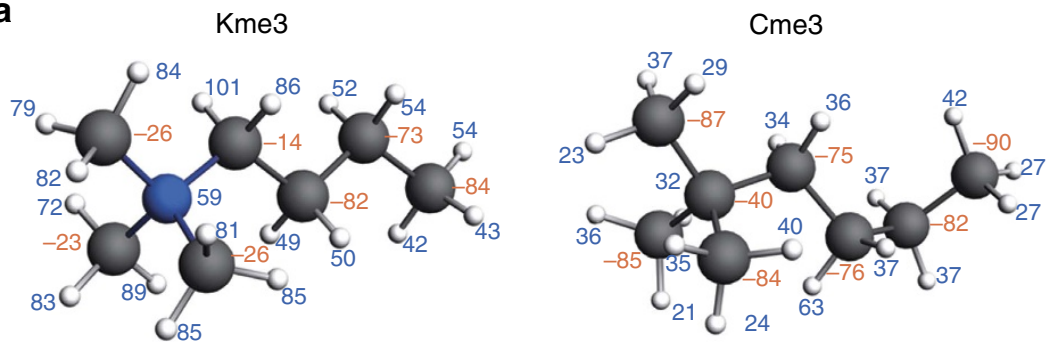

b

Kme3

Cme3

TRP2

LUMO+1
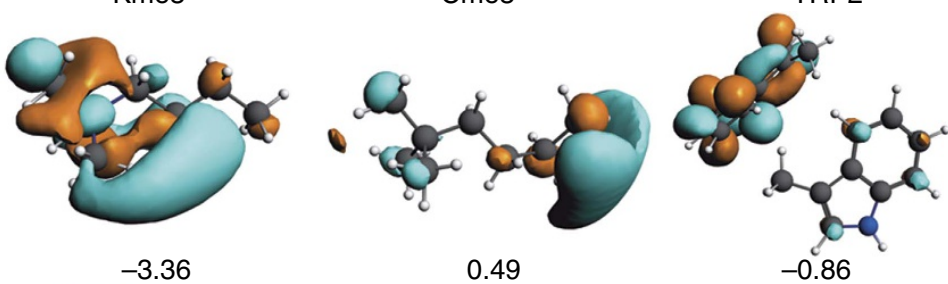

LUMO

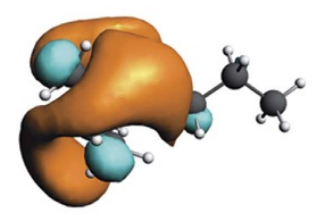

0.49
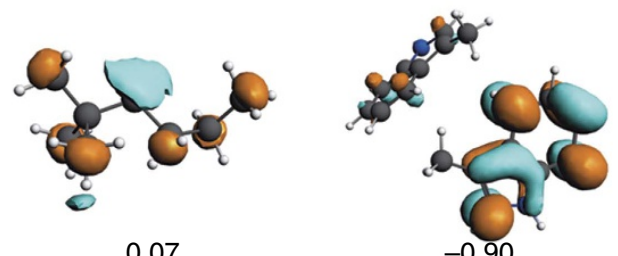

$-4.10$

0.07
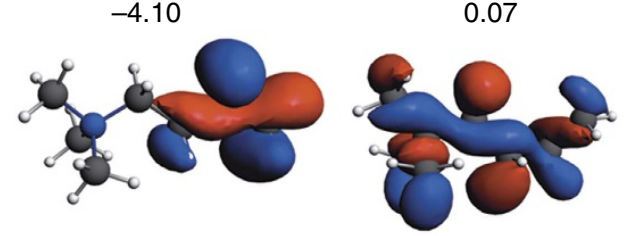

$-11.16$
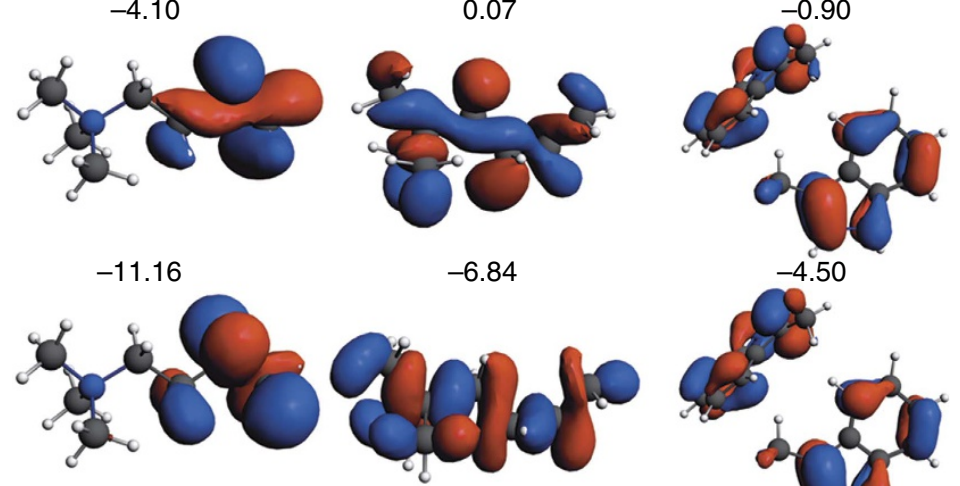

HOMO-1

$-7.04$

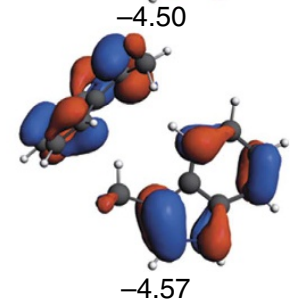

Figure 3 | Computational analysis of TRP2-Kme3 and TRP2-Cme3 interactions. (a) VDD atomic charges (in mili-a.u.) of Kme3 and Cme3, computed at BLYP-D3BJ/TZ2P using X-ray structures of the full systems (red, negative; blue, positive); (b) Frontier orbitals (with orbital energies in eV) of Kme3, Cme3 and TRP2, computed at BLYP-D3BJ/TZ2P using X-ray structures of the full systems (isosurface drawn at 0.03).

favourable enthalpy of the hydration sites in the cage, hence more unfavourable change in enthalpy on displacing those waters on Kme3/Cme3 binding. On the other hand, the BPTF cage is completely surrounded by aromatic residues, producing an enthalpically unfavourable environment for water and therefore a favourable free energy change from water displacement on Kme3/Cme3 binding.

\section{Discussion}

The advances of experimental and theoretical tools developed in the past decade have enabled more extensive analysis of the origins of some genuinely important biomolecular recognition phenomena, including the molecular basis of the hydrophobic effect(s) in protein-ligand interactions and the fundamentals of the receptor-neurotransmitter interactions in neurochemistry ${ }^{27,46}$. This study comprehensively examines the origin of the biomolecular recognition between naturally occurring trimethyllysine-containing histone proteins and their interacting reader proteins that are involved in epigenetic gene regulation processes. We use the physical-organic chemistry approaches, supported by high-resolution structural analyses of reader-histone interactions, to elucidate the molecular/chemical basis of one of the fundamental non-covalent interactions in epigenetics. Analyses of crystal and solution structures of free (unbound) reader proteins and reader-Kme3 complexes have illustrated that the reader's aromatic cage is largely preformed and does not undergo induced fit for binding of histone substrates (Supplementary Fig. 6). The predominantly static nature of the aromatic cage has an advantage over a more flexible recognition site because it minimizes the loss of conformational entropy of the protein on ligand binding 8 . Binding of the flexible and highly unstructured histone to reader proteins, however, results in a significant conformational change of the histone resulting in a more unfavourable entropy of binding for longer histone peptides relative to shorter histone counterparts ${ }^{33}$.

On the basis of the studies of the related proteins that possess the aromatic cages for the recognition of positively charged methylammonium groups, it has been suggested that epigenetic readers recognize Kme3 via cation $-\pi$ interactions $16,27,37,47$. Our 
a

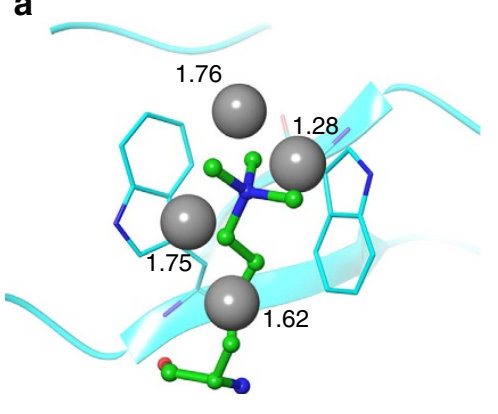

JARID1A

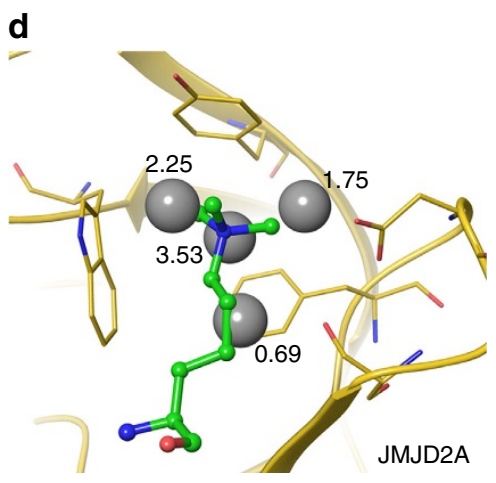

b

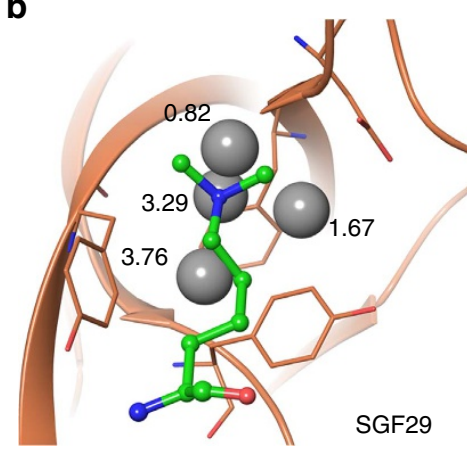

e

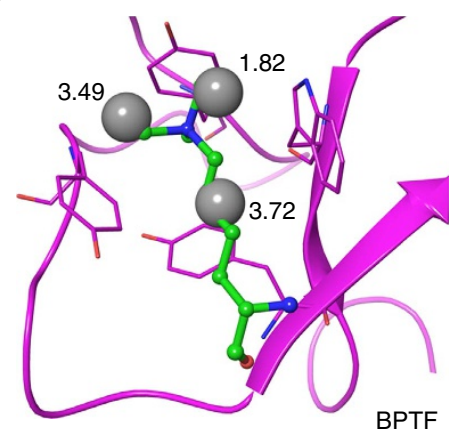

C

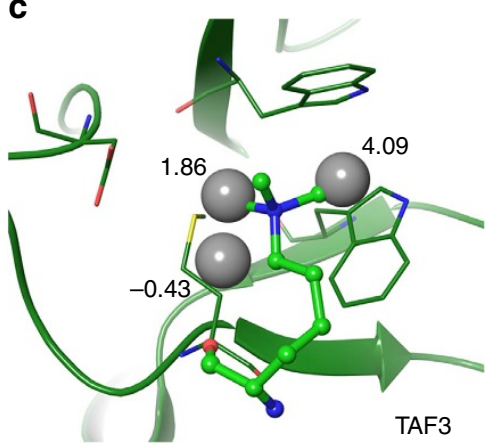

f

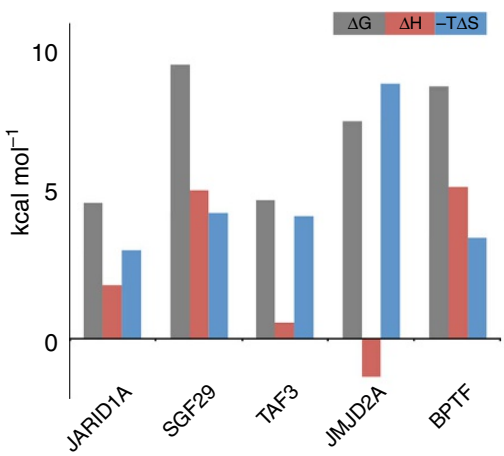

Figure 4 | WaterMap calculations for the solvation of aromatic cages of reader proteins. (a) JARID1A; (b) SGF29; (c) TAF3; (d) JMJD2A;

(e) BPTF. Superimposed Kme3 side chain and water molecules are presented as green stick and grey spheres. Numbers adjacent to grey spheres represent the value of the free energy $(\Delta G)$ for individual water molecule; (f) Thermodynamic parameters for the solvation of the aromatic cages of five reader proteins used in this study.

integrated thermodynamic, structural and computational studies clearly confirm the presence of favourable cation $-\pi$ interactions in the readout of $\mathrm{H} 3 \mathrm{~K} 4 \mathrm{me} 3$ by reader domains of JARID1A, TAF3, BPTF and JMJD2A. Previous examination of the recognition of neutral Cme3 by $\mathrm{HP} 1$ chromodomain, a reader of $\mathrm{H} 3 \mathrm{~K} 9 \mathrm{me} 3$ that contains an aromatic cage comprising two tyrosine and one tryptophan residues, revealed that HP1 binds to $\mathrm{H} 3 \mathrm{C} 9 \mathrm{me} 3$ with substantially lower affinity than $\mathrm{H} 3 \mathrm{~K} 9 \mathrm{me} 3$, thus suggesting that the positive charge of Kme3 is crucial for the association of HP1-H3K9me3 (ref. 16). Comprehensive structural data on JARID1A, TAF3 and SGF29 in complex with $\mathrm{H} 3 \mathrm{C} 4 \mathrm{me} 3$, as described in this work, provide clear evidence that the $\mathrm{Cme} 3$ side chain is well positioned inside the aromatic cages of these three reader proteins in the same manner as the positively charged Kme3 (Fig. 2) and thus enable us to interpret the binding calorimetric data (Table 1). Out of three possible mechanisms (that should always be considered in the interpretation of any protein-ligand system), that is, solutesolute interactions, desolvation of ligand (in this case Kme3) and desolvation of protein (in this case aromatic cage), that govern the recognition of Kme3 by reader proteins, we can exclude desolvation of the Kme3 side chain, because charged residues are highly soluble in aqueous media and have to pay a big desolvation penalty to become desolvated. In this regard, it is essential that the energetically unfavourable desolvation of Kme3 is fully compensated (or more correctly overcompensated) by energetically favourable protein-ligand interactions and protein desolvation to provide a strong binding force for the specific recognition of Kme3 by reader proteins. Based on ITC experiments, our observed enthalpy-driven association of positively charged Kme3 (relative to Cme3) to the electron-rich aromatic cage of several reader proteins has its molecular origin in strong cation $-\pi$ interactions. In addition, the methylene groups of the side chain of Kme3 located within van der Waals distance of the aromatic cages, contribute to the overall binding affinity via weaker, but still favourable, $\mathrm{CH}-\pi$ interactions ${ }^{38,39}$. Our quantum mechanical studies, furthermore, reveal that reader-Kme3 association has the strongest dispersion contribution (similar to reader-Cme3), but that the differences in binding affinities between Kme3 and Cme3 are primarily a result of disparities in electrostatic interactions and orbital interactions (Table 3).

Despite the universally recognized phenomenon that biomolecular processes take place in aqueous media and that the hydrophobic effect is a primary determinant of biomolecular association, the role of explicit water molecules has often been ignored in analyses of biomolecular recognition events ${ }^{48,49}$, although recent advances have enabled more detailed analysis of the role of water molecules in binding ${ }^{46,50,51}$. Energetically favourable desolvation of protein-binding sites, however, often determines the magnitude of protein-ligand association ${ }^{52,53}$. Our observations that binding affinities of H3G4 with JARID1A and TAF3 are drastically reduced when compared with H3K4me3 led to the hypothesis that the aromatic cages are occupied by high-energy water molecules. Although difficult to confirm experimentally, WaterMap calculations performed on five representative reader proteins (both in apo and holo forms) provided evidence that water molecules located inside the aromatic cages exhibit significant unfavourable free energy (Fig. 4 and Supplementary Table 3). These high-energy water molecules are displaced by Kme3 side chain on binding, which consequently provide a substantial favourable contribution to Kme3 binding.

Collectively, the experimental and computational work presented here suggests that the association between trimethyllysinecontaining histones and epigenetic reader domain proteins is driven by favourable cation $-\pi$ interactions and the favourable 
release of high-energy structured water molecules that occupy the aromatic cages of reader proteins. Our study highlights the hitherto neglected, yet essential contribution of water in a molecular readout process in the established area of epigenetics. This study, furthermore, sheds light on the design of small molecule probes that specifically recognize readers of trimethyllysine. In comparison with the advances in development of inhibitors of other epigenetic targets, including bromodomains and various eraser/writer enzymes, there has been very limited success in identification of probes for readers of $\mathrm{Kme} 3$ (refs 54,55). Towards this aim, our study provides valuable experimental and computational data needed for the medicinal chemistry community to design and develop potent and selective small molecule inhibitors with therapeutic potential.

\section{Methods}

General experimental procedures. All experiments were conducted under the following conditions, unless stated otherwise. Commercially available compounds were supplied by commercial sources and used without any further purification. Dry solvents were obtained by purification of HPLC grade solvents over activated alumina column using an MBraun SPS800 solvent purification system. When stated, degassing of solvents was performed for each reaction individually by passing through $\mathrm{N}_{2}(\mathrm{~g})$ for a period of at least $30 \mathrm{~min}$ before use. Compound purification done by column chromatography, was carried out using Silica gel, MerckTM grade (pore size $60 \AA$ A particle size 230-400 mesh, 40-63 $\mu \mathrm{m}$ ). Reaction progress was monitored by glass thin-layer chromatography plates (TLC Silica gel 60G, F254, Merck, Germany) and observed by ultraviolet light and/or by staining in ninhydrin or permanganate. Compound analyses done by ${ }^{1} \mathrm{H} \mathrm{NMR}$, were recorded on a Varian Inova 400 at $400 \mathrm{MHz} .{ }^{13} \mathrm{C}$ NMR data were either recorded using a Bruker Avance III $500 \mathrm{MHz}$ at $125 \mathrm{MHz}$ or a Varian Inova 400 at $101 \mathrm{MHz}$. Reported chemical shifts are in p.p.m., moving from high to low frequency and referenced to the residual solvent resonance. Reported coupling constants $(J)$ are noted in hertz $(\mathrm{Hz})$. To assign multiplicity of signals the following standard abbreviations were used: $s$, singlet; $d$, doublet; $t$, triplet; $q$, quartet; quint, quintet; $m$, multiplet; and br, broad. When possible, ${ }^{1} \mathrm{H}$ assignments were made using appropriate two-dimensional NMR methods, such as correlation spectroscopy, heteronuclear single-quantum correlation spectroscopy and heteronuclear multiple-bond correlation spectroscopy. Mass spectrometry and chromatography analysis were done using a Shimadzu UFLC LC-20AD liquid chromatography/ mass spectrometry system, equipped with a RPC18 $200 \times 2$ guard column. Typical conditions for a run are: $157 \mathrm{bar}$, mobile phase; $2 \min 5 \% \mathrm{MeCN}^{2} \% \mathrm{H}_{2} \mathrm{O}$, in $16 \mathrm{~min}$ decreasing polarity to $100 \% \mathrm{MeCN}, 5 \mathrm{~min}$ of $100 \% \mathrm{MeCN}$, in $2 \mathrm{~min}$ increasing polarity to $95 \% \mathrm{H}_{2} \mathrm{O}$ for $5 \mathrm{~min}$. Ultraviolet/visible detection of this machine was done by Ultraviolet Visible Shimadzu SPD-M20A $(200-600 \mathrm{~nm})$, while mass spectrometry analyses was done using the Thermo scientific LCQ Fleet. HPLC trace analyses were done on a Shimadzu liquid chromatography system; DGU 20A5, using a SPD 20A ultraviolet detector at $214 \mathrm{~nm}$. The machine is equipped with a Gemini-NX 3 C18 column. Typical conditions for a run are: $1 \mathrm{~min}$ at $5 \% \mathrm{MeCN}$ in $95 \% \mathrm{H}_{2} \mathrm{O}$ (with $0.1 \%$ trifluoroacetic acid (TFA)), increase over $30 \mathrm{~min}$ to $100 \%$, keep this for $5 \mathrm{~min}$, then over $5 \mathrm{~min}$ the concentration is decreased to $5 \% \mathrm{MeCN}$ in $95 \% \mathrm{H}_{2} \mathrm{O}$ (with $0.1 \%$ TFA)

Synthesis of Fmoc-L-Cme3. Supplementary Fig. 7 shows the schematic presentation of the synthetic protocol for the preparation of Fmoc-L-Cme3 (6).

Synthesis of (1). Boc-Asp(OH)-OtBu (5.81 g, $20 \mathrm{mmol}, 1$ equivalent), 4-dimethylaminopyridine ( $223.8 \mathrm{mg}, 2 \mathrm{mmol}, 0.1$ equivalents) and $N, N^{\prime}$-dicyclohexylcarbodiimide ( $4.95 \mathrm{~g}, 24 \mathrm{mmol}, 1.2$ equivalents) were dissolved in dry $\mathrm{CH}_{2} \mathrm{Cl}_{2}$ $(40 \mathrm{ml})$ under $\mathrm{N}_{2}$

atmosphere. To this solution was added ethanethiol $(4.7 \mathrm{ml}, 64 \mathrm{mmol} 3.2$ equivalents). After $4 \mathrm{~h}$ of stirring the solvent was removed under reduced pressure. The crude product was purified by column chromatography $\left(\mathrm{SiO}_{2}\right.$, EtOAc in $n$-pentane 5-20\%). This yielded thioester $1(6.26 \mathrm{~g}, 18.8 \mathrm{mmol}, 94 \%)$ as a pale yellow oil: $[\alpha]^{25}+43.4\left(\mathrm{c} 1.00, \mathrm{CH}_{3} \mathrm{Cl}\right)$. FT-IR $\mathrm{v}_{\max }\left(\mathrm{cm}^{-1}\right): 3,436,2,980,2,932$, $1,715,1,688,1,495,1,367,1,250,1,150,1,059,1,023$ and $847 .{ }^{1} \mathrm{H}$ NMR $(400 \mathrm{MHz}$, $\left.\mathrm{CDCl}_{3}\right) \delta: 5.42(\mathrm{~d}, J=8.0 \mathrm{~Hz}, 1 \mathrm{H}, \mathrm{NH}), 4.48-4.36(\mathrm{~m}, 1 \mathrm{H}, \alpha \mathrm{CH}), 3.10(\mathrm{dq}, J=17.0$, $\left.5.0 \mathrm{~Hz}, 2 \mathrm{H}, \beta_{\mathrm{CH}}\right), 2.96-2.78\left(\mathrm{~m}, 2 \mathrm{H}, \mathrm{SCH}_{2}\right), 1.46\left(\mathrm{~s}, 9 \mathrm{H}, \mathrm{C}\left(\mathrm{CH}_{3}\right)_{3}\right), 1.44(\mathrm{~s}, 9 \mathrm{H}$, $\left.\mathrm{C}\left(\mathrm{CH}_{3}\right)_{3}\right)$ and $1.29-1.22\left(\mathrm{~m}, 3 \mathrm{H}, \mathrm{CH}_{3}\right) .{ }^{13} \mathrm{C}$ NMR $\left(101 \mathrm{MHz}^{\left.-\mathrm{CDCl}_{3}\right) \delta: 196.9}\right.$ $169.6,155.2,82.3,79.7,50.8,45.5,28.2,27.8,23.4$ and 14.6. HRMS, calculated for $\mathrm{C}_{15} \mathrm{H}_{27} \mathrm{NO}_{5} \mathrm{SNa}[\mathrm{M}+\mathrm{Na}]^{+} 356.1508$, found 356.1511 .

Synthesis of (2). To a suspension of $\mathrm{Pd} / \mathrm{C}(375 \mathrm{mg}, 10 \% \mathrm{Pd}$ on activated carbon, 6 wt\%) and thioester 1 (6.26 g, $18.8 \mathrm{mmol}, 1$ equivalent) in degassed dry $\mathrm{CH}_{2} \mathrm{Cl}_{2}$ $(40 \mathrm{ml})$ was added triethylsilane $(9 \mathrm{ml}, 56.3 \mathrm{mmol}, 3$ equivalents). The solution was stirred for $90 \mathrm{~min}$, while cooling on a water bath. The black suspension was filtered through celite, concentrated and purified by column chromatography $\left(\mathrm{SiO}_{2}, \mathrm{EtOAc}\right.$ in $n$-heptane 5-25\%). This eventually yielded aldehyde 2 (4.84 g, $17.7 \mathrm{mmol}, 95 \%)$ as a clear colourless oil, which solidified over time: $[\alpha]_{\mathrm{D}}^{25}-24.2$ (c 1.50, EtOH). FT-IR $v_{\max }\left(\mathrm{cm}^{-1}\right): 3,370,2,980,2,935,1,714,1,501,1,368,1,251,1,151,1,054$ and 847. ${ }^{1} \mathrm{H}$ NMR $\left(400 \mathrm{MHz}, \mathrm{CDCl}_{3}\right) \delta: 9.74(\mathrm{~s}, 1 \mathrm{H}, \mathrm{C}(\mathrm{O}) \mathrm{H}), 5.34(\mathrm{~d}, J=7.5 \mathrm{~Hz}, 1 \mathrm{H}$ $\mathrm{NH}), 4.58-4.39(\mathrm{~m}, 1 \mathrm{H}, \alpha \mathrm{CH}), 2.98\left(\mathrm{qd}, J=18.0,5.0 \mathrm{~Hz}, 2 \mathrm{H}, \beta \mathrm{CH}_{2}\right), 1.47(\mathrm{~s}, 9 \mathrm{H}$, $\left.\mathrm{C}\left(\mathrm{CH}_{3}\right)_{3}\right)$ and $1.44\left(\mathrm{~s}, 9 \mathrm{H}, \mathrm{C}\left(\mathrm{CH}_{3}\right)_{3}\right) .{ }^{13} \mathrm{C} \mathrm{NMR}\left(101 \mathrm{MHz} \mathrm{CDCl}_{3}\right) \delta: 199.3,169.8$, 155.3, 82.4, 79.8, 49.2, 46.1, 28.2 and 27.7. HRMS, calculated for $\mathrm{C}_{13} \mathrm{H}_{23} \mathrm{NO}_{5} \mathrm{Na}$ $[\mathrm{M}+\mathrm{Na}]^{+}$296.1474, found 296.1471 .

Synthesis of (3). To a suspension of methyltriphenylphosphonium bromide $\left(2.23 \mathrm{~g}, 6.16 \mathrm{mmol} 1.1\right.$ equivalents) in dry tetrahydrofuran (THF; $30 \mathrm{ml}$ ) under $\mathrm{N}_{2}$ atmosphere, was added NaHMDS $(3.1 \mathrm{ml}, 6.16 \mathrm{mmol}, 2.0 \mathrm{M}$ in THF, 1.1 equivalents). Aldehyde 2 ( $1.08 \mathrm{~g}, 3.66 \mathrm{mmol}, 1$ equivalent) was dissolved in dry THF $(15 \mathrm{ml})$ and added to the solution after $30 \mathrm{~min}$ of stirring. Subsequently, the reaction mixture was stirred for $20 \mathrm{~h}$ and then quenched by the addition of $\mathrm{KHSO}_{4}$ (aq) $(60 \mathrm{ml}, 1 \mathrm{M})$. The aqueous layer was extracted with EtOAc $(3 \times 25 \mathrm{ml})$ and the combined organic extracts were washed with $\mathrm{H}_{2} \mathrm{O}(50 \mathrm{ml})$ and brine $(50 \mathrm{ml})$. The organic layer was dried over $\mathrm{Na}_{2} \mathrm{SO}_{4}$, filtered and evaporated under vacuum. The crude product was purified by silica column chromatography $\left(\mathrm{SiO}_{2}\right.$, EtOAc in $n$ heptane 5-20\%), affording $3(919 \mathrm{mg}, 3.385 \mathrm{mmol}, 60 \%)$ as a clear colourless oil. $[\alpha]^{25}{ }_{\mathrm{D}}+10.3(\mathrm{c} 0.84, \mathrm{MeOH})$. FT-IR $\mathrm{v}_{\max }\left(\mathrm{cm}^{-1}\right): 3,352,2,980,2,933,1,715$, $1,496,1,367,1,251,1,154,918$ and $847 .{ }^{1} \mathrm{H}$ NMR $\left(400 \mathrm{MHz}, \mathrm{CDCl}_{3}\right) \delta: 5.79-5.63$ $\left(\mathrm{m}, 1 \mathrm{H}, \mathrm{CH}_{2}=\mathrm{CH}\right), 5.16-5.09\left(\mathrm{~m}, 2 \mathrm{H}, \mathrm{CH}_{2}=\mathrm{CH}\right), 5.05(\mathrm{~d}, J=7.5 \mathrm{~Hz}, 1 \mathrm{H}, \mathrm{NH})$, $4.25(\mathrm{dd}, J=19.0 \mathrm{~Hz}, 8.5 \mathrm{~Hz} 1 \mathrm{H}, \alpha \mathrm{CH}), 2.63-2.39\left(\mathrm{~m}, 2 \mathrm{H}, \beta \mathrm{CH}_{2}\right), 1.46(\mathrm{~s}, 9 \mathrm{H}$, $\left.\mathrm{C}\left(\mathrm{CH}_{3}\right)_{3}\right)$ and $1.44\left(\mathrm{~s}, 9 \mathrm{H}, \mathrm{C}\left(\mathrm{CH}_{3}\right)_{3}\right) .{ }^{13} \mathrm{C} \mathrm{NMR}\left(101 \mathrm{MHz}, \mathrm{CDCl}_{3}\right) \delta: 171.1,155.2$, 132.5, 118.7, 81.9, 79.6, 53.3, 37.0, 28.3 and 28.0. HRMS, calculated for $\mathrm{C}_{14} \mathrm{H}_{25} \mathrm{NO}_{4} \mathrm{Na}[\mathrm{M}+\mathrm{Na}]^{+} 294.1681$, found 294.1683 .

Synthesis of (4). To a solution of $3(918 \mathrm{mg}, 3.39 \mathrm{mmol}, 1$ equivalent) in dry $\mathrm{CH}_{2} \mathrm{Cl}_{2}(30 \mathrm{ml})$ under $\mathrm{N}_{2}$ atmosphere, were added second generation Grubbs catalyst (434 mg, $0.51 \mathrm{mmol}, 0.15$ equivalents) and 4,4-dimethyl-1-pentene $\left(1,860 \mu \mathrm{l}, 15.54 \mathrm{mmol}, 4\right.$ equivalents). This solution was stirred for $24 \mathrm{~h}$ at $50^{\circ} \mathrm{C}$. After cooling down, the solvent was evaporated under reduced pressure. The crude product was purified by column chromatography $\left(\mathrm{SiO}_{2}\right.$, EtOAc in $n$-heptane $0-10 \%)$, affording $4(650 \mathrm{mg}, 1.9 \mathrm{mmol}, 56 \%)$. [ $\alpha]^{25}{ }_{\mathrm{D}}-5.4(\mathrm{c} 0.93, \mathrm{MeOH})$. FT-IR $\mathrm{v}_{\max }\left(\mathrm{cm}^{-1}\right): 3,337,2,954,1,716,1,495,1,365,1,248,1,153,970$ and $847 .{ }^{1} \mathrm{H} \mathrm{NMR}$ $\left(400 \mathrm{MHz}, \mathrm{CDCl}_{3}\right)$ (Z: E ratio 1: 4.7 , most abundant isomer) $\delta: 5.49-5.58(\mathrm{~m}, 1 \mathrm{H}$, $\mathrm{CH}=\mathrm{CH}), 5.32-5.20(\mathrm{~m}, 1 \mathrm{H}, \mathrm{CH}=\mathrm{CH}), 5.01(\mathrm{~d}, J=8.0 \mathrm{~Hz}, 1 \mathrm{H}, \mathrm{NH}), 4.29-4.16$ (m, $1 \mathrm{H}, \alpha \mathrm{CH}), 2.54-2.33\left(\mathrm{~m}, 2 \mathrm{H}, \beta \mathrm{CH}_{2}\right), 1.88\left(\mathrm{dd}, J=7.5,1.0 \mathrm{~Hz}, 2 \mathrm{H}, \varepsilon \mathrm{CH}_{2}\right), 1.47$ (s, 9H, C( $\left.\left.\mathrm{CH}_{3}\right)_{3}\right), 1.44\left(\mathrm{~s}, 9 \mathrm{H}, \mathrm{C}\left(\mathrm{CH}_{3}\right)_{3}\right)$ and $0.87\left(\mathrm{~s}, 9 \mathrm{H}, \mathrm{C}\left(\mathrm{CH}_{3}\right)_{3}\right) .{ }^{13} \mathrm{C} \mathrm{NMR}$ $\left(126 \mathrm{MHz}, \mathrm{CDCl}_{3}\right) \delta: 171.4,155.1,132.2,125.8,81.7,79.5,53.6,47.1,35.8,30.8$, 29.3, 28.3 and 28.1. HRMS, calculated for $\mathrm{C}_{19} \mathrm{H}_{35} \mathrm{NO}_{4} \mathrm{Na}[\mathrm{M}+\mathrm{Na}]{ }^{+}$364.2464, found 364.2478 .

Synthesis of (5). To a suspension of $\mathrm{Pd} / \mathrm{C}(140 \mathrm{mg}, 10 \% \mathrm{Pd}$ on activated carbon $25 \mathrm{wt} \%)$ in dry $\mathrm{CH}_{2} \mathrm{Cl}_{2}(20 \mathrm{ml})$, was added $4(558 \mathrm{mg}, 1.63 \mathrm{mmol}, 1$ equivalent). The solution was vigorously stirred under $\mathrm{H}_{2}$ atmosphere for $24 \mathrm{~h}$. The black suspension was filtered through celite and washed with $\mathrm{CH}_{2} \mathrm{Cl}_{2}(3 \times 25 \mathrm{ml})$. The filtrate was concentrated under reduced pressure yielding $5(530 \mathrm{mg}, 1.54 \mathrm{mmol}$, $95 \%)$ as a slightly brown oil. $[\alpha]^{25}-14.0$ (c 1.00, MeOH). FT-IR $\mathrm{v}_{\max }\left(\mathrm{cm}^{-1}\right)$ : $3,350,2,954,2,865,1,770,1,498,1,392,1,366,1,249,1,154$ and $849 .{ }^{1} \mathrm{H}$ NMR $\left(500 \mathrm{MHz}, \mathrm{CDCl}_{3}\right) \delta: 4.92(\mathrm{~d}, J=8.0 \mathrm{~Hz}, 1 \mathrm{H}, \mathrm{NH}), 4.09(\mathrm{dd}, J=13.0,7.0 \mathrm{~Hz}, 1 \mathrm{H}$, $\alpha \mathrm{CH}), 1.60-1.48\left(\mathrm{~m}, 2 \mathrm{H}, \beta \mathrm{CH}_{2}\right), 1.40\left(\mathrm{~s}, 9 \mathrm{H}, \mathrm{C}\left(\mathrm{CH}_{3}\right)_{3}\right), 1.37\left(\mathrm{~s}, 9 \mathrm{H}, \mathrm{C}\left(\mathrm{CH}_{3}\right)_{3}\right)$, 1.30-1.13 $\left(\mathrm{m}, 4 \mathrm{H}, \gamma \mathrm{CH}_{2}\right.$ and $\left.\delta \mathrm{CH}_{2}\right), 1.12-1.04\left(\mathrm{~m}, 2 \mathrm{H}, \varepsilon \mathrm{CH}_{2}\right)$ and $0.79(\mathrm{~s}, 9 \mathrm{H}$, $\left.\mathrm{C}\left(\mathrm{CH}_{3}\right)_{3}\right) .{ }^{13} \mathrm{C} \mathrm{NMR}\left(126 \mathrm{MHz}, \mathrm{CDCl}_{3}\right) \delta: 172.2,155.4,81.6,79.5,54.0,44.0,33.0$, $30.3,29.4,28.4,28.0,26.1$ and 24.3. HRMS, calculated for $\mathrm{C}_{19} \mathrm{H}_{37} \mathrm{NO}_{4} \mathrm{Na}[\mathrm{M}+$ $\mathrm{Na}]^{+}$366.2620, found 366.2619 .

Synthesis of (6). Protected 5 (295 $\mathrm{mg}, 0.86 \mathrm{mmol}, 1$ equivalent) was dissolved in a mixture of TFA: dichloromethane $(30 \mathrm{ml}, 2: 1)$ and left stirring for $5 \mathrm{~h}$. The solvent was removed under vacuum and the resulting crude product was redissolved in $\mathrm{H}_{2} \mathrm{O}$ : dioxane $(30 \mathrm{ml}, 1: 1)$ and the $\mathrm{pH}$ of the solution was adjusted to $\mathrm{pH} 8-9$ by the addition of $\mathrm{NaHCO}_{3}$. Subsequently, Fmoc-OSu (435 mg, 1.29 mmol, 1.5 equivalents) was added to the solution. After stirring for $16 \mathrm{~h}$ the solution was acidified to $\mathrm{pH} 3$ by addition of $\mathrm{HCl}_{(\mathrm{aq})}(1 \mathrm{M})$ and extracted with EtOAc $(5 \times 20 \mathrm{ml})$. The combined organic extracts were washed with brine $(50 \mathrm{ml})$, dried over $\mathrm{Na}_{2} \mathrm{SO}_{4}$, filtered and concentrated under reduced pressure. The crude oil was purified by column chromatography $\left(\mathrm{SiO}_{2}, \mathrm{MeOH}\right.$ in $\mathrm{CH}_{2} \mathrm{Cl}_{2}$ and a few drops of $\mathrm{AcOH}$, $1-4 \%)$, affording $6(295 \mathrm{mg}, 0.72 \mathrm{mmol}, 84 \%)$ as a clear viscous oil. $[\alpha]^{25}{ }_{\mathrm{D}}-2.5$ (c $0.16, \mathrm{MeOH})$. FT-IR $\mathrm{v}_{\max }\left(\mathrm{cm}^{-1}\right): 3,326,2,952,2,862,1,710,1,520,1,451,1,214$, 1,079, 758 and 739. ${ }^{1} \mathrm{H}$ NMR $\left(400 \mathrm{MHz} \mathrm{CDCl}_{3}\right) \delta: 7.77(\mathrm{~d}, J=6.0 \mathrm{~Hz}, 2 \mathrm{H}$, $2 \times \mathrm{ArCH}), 7.64-7.50(\mathrm{~m}, 2 \mathrm{H}, 2 \times \mathrm{ArCH}), 7.40(\mathrm{t}, J=7.4 \mathrm{~Hz}, 2 \mathrm{H}, 2 \times \mathrm{ArCH}), 7.31$ $(\mathrm{t}, J=7.0,2 \mathrm{H}, 2 \times \mathrm{ArCH}), 5.37-5.20(\mathrm{~m}, 1 \mathrm{H}, \mathrm{NH}), 4.54-4.33(\mathrm{~m}, 3 \mathrm{H}, \alpha \mathrm{CH}$ and $\left.\mathrm{OCH}_{2}\right), 4.28-4.17(\mathrm{~m}, 1 \mathrm{H}, \mathrm{CH}), 1.97-1.82(\mathrm{~m}, 1 \mathrm{H}, \beta \mathrm{CH}), 1.78-1.66(\mathrm{~m}, 1 \mathrm{H}, \beta \mathrm{CH})$, 1.44-1.10 $\left(\mathrm{m}, 6 \mathrm{H}, \gamma \mathrm{CH}_{2}\right.$ and $\delta \mathrm{CH}_{2}$ and $\left.\varepsilon \mathrm{CH}_{2}\right)$ and $0.86\left(\mathrm{~s}, 9 \mathrm{H}, \mathrm{C}\left(\mathrm{CH}_{3}\right)_{3}\right) .{ }^{13} \mathrm{C}$ $\operatorname{NMR}\left(126 \mathrm{MHz}, \mathrm{CDCl}_{3}\right) \delta: 177.5,156.1,143.9,141.3,127.7,127.1,124.9,120.0$, 67.1, 53.9, 47.2, 43.9, 32.4, 30.3, 29.4, 26.1 and 24.2. HRMS, calculated for $\mathrm{C}_{25} \mathrm{H}_{31} \mathrm{NO}_{4} \mathrm{Na}[\mathrm{M}+\mathrm{Na}]^{+} 432.2151$, found 432.2153 . 
Solid-phase peptide synthesis. Ten mer histone peptides were synthesized by solid-phase peptide synthesis applying Fmoc chemistry. Peptides contain a carboxylic acid at the $\mathrm{C}$ terminus and were made on Wang resin and couplings were done in dimethylformamide (DMF) with Fmoc-protected amino acid (3.0 equivalents), diisopropylcarbodiimide (3.3 equiv.) and hydroxybenzotriazole (3.6 equivalents). Completion of the reaction was determined with the Kaiser test, and removal of Fmoc was achieved by treatment with a large excess of piperidine $(20 \%)$ in DMF for 20-30 min. Every wash step was performed with $3 \times$ DMF and after building completion the Fmoc was removed followed by wash $3 \times$ DMF and $3 \times$ $\mathrm{Et}_{2} \mathrm{O}$ continued by drying of the resin in vacuo. The peptides were cleaved from the resin by a mixture of TFA $(92.5 \%), \mathrm{H}_{2} \mathrm{O}(2.5 \%)$, tri-isopropylsilane $(2.5 \%)$ and ethane-1,2-dithiol (2.5\%). After mixing and shaking for

$4-5 \mathrm{~h}$, the product peptide was precipitated in $\mathrm{Et}_{2} \mathrm{O}$, and the $\mathrm{Et}_{2} \mathrm{O}$ was decanted after centrifugation (3,500 r.p.m., 3 min, Hermle 220.72 v04). Histone peptides were analysed by liquid chromatography-mass spectrometry and purified by preparative HPLC (Supplementary Figs 8-13). Purified histone peptides were analysed by ${ }^{19} \mathrm{~F}$ NMR spectroscopy, which provided evidence that they appear as TFA salts.

Preparation and purification of reader proteins. Reader proteins were prepared and purified following the previously reported procedure ${ }^{33}$. Briefly, the reader domains of BPTF, JMJD2A, JARID1A, TAF3 and SGF29 were expressed in Escherichia coli Rosetta BL21 DE3 pLysS hosts, using Terrific Broth medium. The bacteria were cultured to $\mathrm{OD} 600 \sim 0.6$ at $37^{\circ} \mathrm{C}$ after which they were induced with $0.5 \mathrm{mM}$ isopropyl-b-D-thiogalactoside overnight at $16^{\circ} \mathrm{C}$. Proteins were purified using Ni-NTA beads for 6 xHis-tagged proteins or glutathione sepharose beads for GST tagged proteins, respectively. After purification, the $6 \mathrm{xH}$ is tag was cleaved from JMJD2A and SGF29 using TEV-protease and the GST tag was cleaved from TAF3 using thrombin. Protein were purified by size-exclusion chromatography using a Superdex 75 column (GE Healthcare). SGF29 was eluted in $25 \mathrm{mM}$ Tris, $50 \mathrm{mM} \mathrm{NaCl}, 1 \mathrm{mM}$ dithiothreitol at $\mathrm{pH}$ 7.5; JMJD2A and TAF3 were eluted in $50 \mathrm{mM}$ Tris at pH 7.5; BPTF and JARID1A were eluted in $50 \mathrm{mM}$ Tris, $20 \mathrm{mM}$ $\mathrm{NaCl}$ at $\mathrm{pH}$ 7.5. All proteins were made filter sterile and stored at $4{ }^{\circ} \mathrm{C}$ until further use.

Isothermal titration calorimetry. Concentrations of histone peptides were measured by ultraviolet spectroscopy at $205 \mathrm{~nm}$, following the previously reported method $^{56}$. All histone peptides were titrated to the same batch of reader proteins. Generally, $350-600 \mu \mathrm{M}$ of $\mathrm{H} 3 \mathrm{~K} 4 \mathrm{me} 3$ or $\mathrm{H} 3 \mathrm{C} 4 \mathrm{me} 3$ peptides were titrated to $25-40 \mu \mathrm{M}$ of protein, except for JMJD2A-H3C4me3 (200 $\mu \mathrm{M}$ JMJD2A, $3 \mathrm{mM}$ H3C4me3). H3G4 $(5 \mathrm{mM})$ was titrated to JARID1A $(330 \mu \mathrm{M})$ and H3G4 $(3 \mathrm{mM})$ was titrated to TAF3 $(200 \mu \mathrm{M})$. Each ITC titration consisted of 19 injections. ITC experiments were performed on the fully automated Microcal Auto-iTC200 (GE Healthcare Life Sciences, USA). Heats of dilution for histone peptides were determined in control experiments, and were subtracted from the titration binding data before curve fitting. Curve fitting was performed by Origin 6.0 (Microcal Inc., USA) using one set of sites binding model. For each reader-histone system, 5-7 independent ITC experiments were carried out. Measurements of heat capacities were typically done in the interval of $10-30^{\circ} \mathrm{C}$, in triplicate at each temperature.

X-ray crystallography. The tandem tudor domain of human SGF29 (residues 115-293) was cloned into a pET-28a-MHL vector, and is expressed, purified as described before ${ }^{22}$. The purified SGF29 is concentrated to $20 \mathrm{mg} \mathrm{ml}^{-1}$ as a stock and frozen at $-80^{\circ} \mathrm{C}$ for future use. Purified SGF29 $\left(15 \mathrm{mg} \mathrm{ml}^{-1}\right)$ was mixed with histone peptide $\mathrm{H} 3 \mathrm{C} 4 \mathrm{me} 3$ in a molecular ratio of $1: 3$, and the complex was crystallized in a buffer containing $0.1 \mathrm{M}$ Bis-Tris, pH 5.5, 27\% PEG3350, $200 \mathrm{mM}$ ammonium sulphate and $5 \mathrm{mM}$ strontium chloride. Before flash-frozen in liquid nitrogen, the crystals were soaked in a cryoprotectant buffer containing $88 \%$ reservoir solution and $12 \%$ glycerol.

Human JARID1A PHD finger (aa 330-380) was PCR amplified, and cloned into a modified pET28b vector (Novagen) with an N-terminal 10xHis-SUMO tandem tag. JARID1A PHD finger used for crystallization was expressed in the E. coli BL21 (Novagen) induced overnight by $0.2 \mathrm{mM}$ isopropyl $\beta$-D-thiogalactoside at $25^{\circ} \mathrm{C}$ in the $\mathrm{LB}$ medium supplemented with $0.1 \mathrm{mM} \mathrm{ZnCl}$. The collected cells were suspended in $500 \mathrm{mM} \mathrm{NaCl}, 20 \mathrm{mM}$ Tris, $\mathrm{pH}$ 8.5. After cell lysis and centrifugation, the supernatant was applied to a HisTrap (GE Healthcare) column and the protein was eluted with a linear imidazole gradient from $20 \mathrm{mM}$ to $500 \mathrm{mM}$, followed by tag cleavage using ULP1. A HisTrap column was used to remove the cleaved 10xHis-SUMO tag after removal of imidazole by desalting. The JARID1A PHD sample flow-through was then pooled, concentrated and polished by size-exclusion chromatography on a Superdex $7516 / 60$ column (GE Healthcare) under the elution buffer: $150 \mathrm{mM} \mathrm{NaCl}, 20 \mathrm{mM}$ Tris, $\mathrm{pH}$ 8.5. The resultant peak of JARID1A PHD finger was then concentrated to $\sim 17 \mathrm{mg} \mathrm{ml}^{-1}$, split into small aliquots and frozen in liquid nitrogen for future use.

As for human TAF3, the PHD finger construct 885-915 was cloned, expressed and purified using essentially the same strategy as JARID1A PHD finger. TAF3 PHD finger was concentrated to $\sim 25 \mathrm{mg} \mathrm{ml}^{-1}$ and aliquoted for future use.
Crystallization was performed via the sitting drop vapour diffusion method under $4{ }^{\circ} \mathrm{C}$ by mixing equal volume $(0.2-1.0 \mu \mathrm{l})$ of JARID1A PHD-H3C4me3 complex (1:1.8 molar ratio, $\left.14-16 \mathrm{mg} \mathrm{ml}^{-1}\right)$ and reservoir solution containing $0.02 \mathrm{M}$ sodium-l-glutamate, $0.02 \mathrm{M}$ DL-alanine, $0.02 \mathrm{M}$ glycine, $0.02 \mathrm{M}$ DL-lysine $\mathrm{HCl}, 0.02 \mathrm{M}$ DL-serine, $0.1 \mathrm{M}$ Tris, $0.1 \mathrm{M}$ Bicine, $\mathrm{pH}$ 8.5, 12.5\% MPD, $12.5 \%$ PEG $1 \mathrm{~K}, 12.5 \%$ PEG3350. As for TAF3 PHD-H3C4me3 complex (1:1.4 molar ratio, $22-24 \mathrm{mg} \mathrm{ml}^{-1}$ ), the crystal was grown in the reservoir solution containing $0.03 \mathrm{M}$ magnesium chloride, $0.03 \mathrm{M}$ calcium chloride, $0.1 \mathrm{M}$ MES, $0.1 \mathrm{M}$ imidazole, $\mathrm{pH} 6.5,15 \%$ PEGMME 550, 15\% PEG $20 \mathrm{~K}$. The complex crystals were directly flash-frozen in liquid nitrogen with reservoir solution as cryoprotectant for data collection. The diffraction data were collected at the beamline BL17U of the Shanghai Synchrotron Radiation Facility at $0.9793 \AA$ A. All diffraction images were indexed, integrated and merged using HKL2000 (ref. 57). The structure was determined by molecular replacement using MOLREP $^{58}$ with the free JARID1A PHD finger (PDB ID: 2KGG) and free TAF3 PHD finger (PDB ID: 2K16) as the search model. Structural refinement was carried out using PHENIX ${ }^{59}$, and iterative model building was performed with $\mathrm{COOT}^{60}$. Detailed data collection and refinement statistics are summarized in Table 2. Structural figures were created using the PYMOL (http://www.pymol.org/) program.

Quantum-chemical analyses. All calculations for TRP2-Kme3 and TRP2-Cme3 complexes were carried out with the ADF program using dispersion-corrected density functional theory at the BLYP-D3BJ/TZ2P level of theory ${ }^{40,41}$. The effect of solvation was simulated by means of the Conductor like Screening Model (COSMO) of solvation as implemented in ADF. The approach has been benchmarked against highly correlated post-Hartree-Fock methods and experimental data and was found to work reliably ${ }^{61-63}$

The bonding mechanism in our model complexes have been further analysed using quantitative (Kohn-Sham) molecular orbital theory in combination with an $\mathrm{EDA}^{42,64}$. The bond energy in aqueous solution $\Delta E(\mathrm{aq})$ consists of two major components, namely, the strain energy $\Delta E_{\text {strain }}(\mathrm{aq})$ associated with deforming the Kme3 (or Cme3) and the reader from their own equilibrium structure to the geometry they adopt in the complex, plus the interaction energy $\Delta E_{\text {int }}($ aq) between these deformed solutes in the complex (see equation (1)):

$$
\Delta E(\mathrm{aq})=\Delta E_{\text {strain }}(\mathrm{aq})+\Delta E_{\text {int }}(\mathrm{aq}) .
$$

To arrive at an understanding of the importance of desolvation phenomena during the complexation process, we separate the interaction energy $\Delta E_{\text {int }}($ aq $)$ into the effect caused by the change in solvation $\Delta E$ (desolv) and the remaining intrinsic solute-solute interaction $\Delta E_{\text {int }}$ between the unsolvated fragments in vacuum:

$$
\Delta E_{\text {int }}(\mathrm{aq})=\Delta E_{\text {int }}(\text { desolv })+\Delta E_{\text {int }} .
$$

In the EDA, the intrinsic interaction energy $\Delta E_{\text {int }}$ can be further decomposed as shown in equation (3):

$$
\Delta E_{\text {int }}=\Delta V_{\text {elstat }}+\Delta E_{\text {Pauli }}+\Delta E_{\text {oi }}+\Delta E_{\text {disp }} .
$$

Here $\Delta V_{\text {elstat }}$ corresponds to the classical electrostatic interaction between the unperturbed charge distributions of the deformed fragments that is usually attractive. The Pauli repulsion $\Delta E_{\text {Pauli }}$ comprises the destabilizing interactions between occupied orbitals and is responsible for the steric repulsions. The orbital interaction $\Delta E_{\mathrm{oi}}$ accounts for charge transfer (donor-acceptor interactions between occupied orbitals on one moiety with unoccupied orbitals of the other, including the HOMO-LUMO interactions) and polarization (empty/occupied orbital mixing on one fragment due to the presence of another fragment). Finally, the $\Delta E_{\text {disp }}$ term accounts for the dispersion interactions based on Grimme's DFT-D3BJ correction. Furthermore, the charge distribution has been analysed using the VDD method ${ }^{43}$.

WaterMap calculations. WaterMap has been described in detail in previous works ${ }^{52,65}$. All calculations were run in with default settings. In brief, a $2 \mathrm{~ns}$ molecular dynamic simulation of the reader proteins with the peptide removed, is performed using the Desmond molecular dynamic engine ${ }^{66,67}$ with the OPLS2.1 force field ${ }^{68,69}$. Protein atoms are constrained throughout the simulation. Water molecules from the simulation are then clustered into distinct hydration sites. Enthalpy values for each hydration site are obtained by averaging over the non-bonded interaction for each water molecule in the cluster. Entropy values are calculated using a numerical integration of a local expansion of the entropy in terms of spatial and orientational correlation functions ${ }^{44,45}$. The contribution of water-free energy to the binding free energy of the peptide is approximated by the sum of the free energies of hydration sites displaced by the ligand on binding.

\section{References}

1. Allis, C. D., Jenuwein, T. \& Reinberg, D. Epigenetics (Cold Spring Harbor Laboratory Press, 2007).

2. Kouzarides, T. Chromatin modifications and their function. Cell 128, 693-705 (2007).

3. Strahl, B. D. \& Allis, C. D. The language of covalent histone modifications. Nature 403, 41-45 (2000). 
4. Zhang, Y. \& Reinberg, D. Transcription regulation by histone methylation: Interplay between different covalent modifications of the core histone tails. Genes Dev. 15, 2343-2360 (2001).

5. Martin, C. \& Zhang, Y. The diverse functions of histone lysine methylation. Nat. Rev. Mol. Cell Biol. 6, 838-849 (2005).

6. Cloos, P. A. C., Christensen, J., Agger, K. \& Helin, K. Erasing the methyl mark: Histone demethylases at the center of cellular differentiation and disease. Genes Dev. 22, 1115-1140 (2008).

7. Yun, M., Wu, J., Workman, J. L. \& Li, B. Readers of histone modifications. Cell Res. 21, 564-578 (2011).

8. Taverna, S. D., Li, H., Ruthenburg, A. J., Allis, C. D. \& Patel, D. J. How chromatin-binding modules interpret histone modifications: lessons from professional pocket pickers. Nat. Struct. Mol. Biol. 14, 1025-1040 (2007).

9. Min, J. et al. L3MBTL1 recognition of mono- and dimethylated histones. Nat. Struct. Mol. Biol. 14, 1229-1230 (2007).

10. Li, H. et al. Structural basis for lower lysine methylation state-specific readout by MBT repeats of L3MBTL1 and an engineered PHD finger. Mol. Cell 28, 677-691 (2007)

11. Botuyan, M. V. et al. Structural basis for the methylation state-specific recognition of histone $\mathrm{H} 4-\mathrm{K} 20$ by 53BP1 and Crb2 in DNA repair. Cell 127, 1361-1373 (2006).

12. Kuo, A. J. et al. The BAH domain of ORC1 links H4K20me2 to DNA replication licensing and Meier-Gorlin syndrome. Nature 484, 115-119 (2012).

13. Collins, R. E. et al. The ankyrin repeats of G9a and GLP histone methyltransferases are mono- and dimethyllysine binding modules. Nat. Struct. Mol. Biol. 15, 245-250 (2008).

14. Sims, R. J. \& Reinberg, D. Histone H3 Lys 4 methylation: caught in a bind? Genes Dev. 20, 2779-2786 (2006).

15. Iwase, S. et al. ATRX ADD domain links an atypical histone methylation recognition mechanism to human mental-retardation syndrome. Nat. Struct. Mol. Biol. 18, 769-776 (2011)

16. Hughes, R. M., Wiggins, K. R., Khorasanizadeh, S. \& Waters, M. L. Recognition of trimethyllysine by a chromodomain is not driven by the hydrophobic effect. Proc. Natl Acad. Sci. USA 104, 11184-11188 (2007).

17. Ruthenburg, A. J., Allis, C. D. \& Wysocka, J. Methylation of lysine 4 on histone H3: intricacy of writing and reading a single epigenetic mark. Mol. Cell 25, 15-30 (2007).

18. Zhenyu, L., Lai, J. \& Yingkai, Z. Importance of charge independent effects in readout of the trimethyllysine mark by HP1 chromodomain. J. Am. Chem. Soc. 131, 14928-14931 (2009).

19. Wang, G. G. et al. Haematopoietic malignancies caused by dysregulation of a chromatin-binding PHD finger. Nature 459, 847-851 (2009).

20. Li, H. et al. Molecular basis for site-specific read-out of histone H3K4me3 by the BPTF PHD finger of NURF. Nature 442, 91-95 (2006).

21. van Ingen, H. et al. Structural insight into the recognition of the H3K4me3 mark by the TFIID subunit TAF3. Structure 16, 1245-1256 (2008).

22. Bian, C. et al. Sgf 29 binds histone H3K4me2/3 and is required for SAGA complex recruitment and histone $\mathrm{H} 3$ acetylation. EMBO J. 30, 2829-2842 (2011).

23. Lee, J., Thompson, J. R., Botuyan, M. V. \& Mer, G. Distinct binding modes specify the recognition of methylated histones H3K4 and H4K20 by JMJD2A-tudor. Nat. Struct. Mol. Biol. 15, 109-111 (2008).

24. Ma, J. C. \& Dougherty, D. A. The Cation $-\pi$ Interaction. Chem. Rev. 97, 1303-1324 (1997).

25. Dougherty, D. A. Cation- $\pi$ interactions in chemistry and biology: a new view of benzene, Phe, Tyr, and Trp. Science 271, 163-168 (1996).

26. Gallivan, J. P. \& Dougherty, D. A. Cation- $\pi$ interactions in structural biology. Proc. Natl Acad. Sci. USA 96, 9459-9464 (1999).

27. Dougherty, D. A. The cation- $\pi$ interaction. Acc. Chem. Res. 46, 885-893 (2013).

28. Nagy, G. N. et al. Composite aromatic boxes for enzymatic transformations of quaternary ammonium substrates. Angew. Chem. Int. Ed. 53, 13471-13476 (2014).

29. Cubero, E., Luque, F. J. \& Orozco, M. Is polarization important in cation-pi interactions? Proc. Natl Acad. Sci. USA 95, 5976-5980 (1998).

30. Hunter, C. A., Low, C. M. R., Rotger, C., Vinter, J. G. \& Zonta, C. Substituent effects on cation- $\pi$ interactions: a quantitative study. Proc. Natl Acad. Sci. USA 99, 4873-4876 (2002).

31. Wheeler, S. E. \& Houk, K. N. Substituent effects in cation $/ \pi$ interactions and electrostatic potentials above the centers of substituted benzenes are due primarily to through-space effects of the substituents. J. Am. Chem. Soc. 131, 3126-3127 (2009).

32. Zhong, W. et al. From ab initio quantum mechanics to molecular neurobiology: a cation- $\pi$ binding site in the nicotinic receptor. Proc. Natl Acad. Sci. USA 95, 12088-12093 (1998).

33. Pieters, B., Belle, R. \& Mecinović, J. The effect of the length of histone H3K4me3 on recognition by reader proteins. Chembiochem 14, 2408-2412 (2013).

34. Southall, N. T., Dill, K. A. \& Haymet, A. D. J. A view of the hydrophobic effect. J. Phys. Chem. B 106, 521-533 (2002).

35. Chandler, D. Interfaces and the driving force of hydrophobic assembly. Nature 437, 640-647 (2005).
36. Blokzijl, W. \& Engberts, J. B. F. N. Hydrophobic Effects. Opinions and Facts. Angew. Chem. Int. Ed. 32, 1545-1579 (1993).

37. Salonen, L. M., Ellermann, M. \& Diederich, F. Aromatic rings in chemical and biological recognition: energetics and structures. Angew. Chem. Int. Ed. 50, 4808-4842 (2011).

38. Nishio, M., Umezawa, Y., Fantini, J., Weiss, M. S. \& Chakrabarti, P. CH- $\pi$ hydrogen bonds in biological macromolecules. Phys. Chem. Chem. Phys. 16, 12648-12683 (2014).

39. Takahashi, O., Kohno, Y. \& Nishio, M. Relevance of weak hydrogen bonds in the conformation of organic compounds and bioconjugates: Evidence from recent experimental data and high-level ab initio MO calculations. Chem. Rev. 110, 6049-6076 (2010).

40. te Velde, G. et al. Chemistry with ADF. J. Comput. Chem. 22, 931-967 (2001)

41. Becke, A. D. Density-functional exchange-energy approximation with correct asymptotic behavior. Phys. Rev. A 38, 3098-3100 (1988).

42. Bickelhaupt, F. M. \& Baerends, E. J. Reviews in Computational Chemistry Vol. 15, 1-86 (Wiley, 2000).

43. Fonseca Guerra, C., Handgraaf, J. W., Baerends, E. J. \& Bickelhaupt, F. M. Voronoi deformation density (VDD) charges: assessment of the Mulliken, Bader, Hirshfeld, Weinhold, and VDD methods for charge analysis. J. Comput Chem. 25, 189-210 (2004).

44. Lazaridis, T. Inhomogeneous fluid approach to solvation thermodynamics. 1. Theory. J. Phys. Chem. B 102, 3531-3541 (1998).

45. Lazaridis, T. Inhomogeneous fluid approach to solvation thermodynamics. 2. applications to simple fluids. J. Phys. Chem. B 102, 3542-3550 (1998).

46. Snyder, P. W. et al. Mechanism of the hydrophobic effect in the biomolecular recognition of arylsulfonamides by carbonic anhydrase. Proc. Natl Acad. Sci. USA 108, 17889-17894 (2011).

47. Persch, E., Dumele, O. \& Diederich, F. Molecular recognition in chemical and biological systems. Angew. Chem. Int. Ed. 54, 3290-3327 (2015).

48. Snyder, P. W., Lockett, M. R., Moustakas, D. T. \& Whitesides, G. M. Is it the shape of the cavity, or the shape of the water in the cavity? Eur. Phys. J. Spec. Top. 223, 853-891 (2014).

49. Ball, P. Water as an active constituent in cell biology. Chem. Rev. 108, 74-108 (2008).

50. Krimmer, S. G., Betz, M., Heine, A. \& Klebe, G. Methyl, ethyl, propyl, butyl: Futile but not for water, as the correlation of structure and thermodynamic signature shows in a congeneric series of thermolysin inhibitors. ChemMedChem 9, 833-846 (2014).

51. Breiten, B. et al. Water networks contribute to enthalpy/entropy compensation in protein-ligand binding. J. Am. Chem. Soc. 135, 15579-15584 (2013).

52. Beuming, T. et al. Thermodynamic analysis of water molecules at the surface of proteins and applications to binding site prediction and characterization. Proteins 80, 871-883 (2012).

53. Sirin, S., Pearlman, D. A. \& Sherman, W. Physics-based enzyme design: predicting binding affinity and catalytic activity. Proteins 82, 3397-3409 (2014).

54. Arrowsmith, C. H., Bountra, C., Fish, P. V., Lee, K. \& Schapira, M. Epigenetic protein families: a new frontier for drug discovery. Nat. Rev. Drug Discov. 11, 384-400 (2012).

55. Sippl, W. \& Jung, M. Epigenetic Targets in Drug Discovery Vol. 42 (Wiley-VCH Verlag GmbH, 2009).

56. Anthis, N. J. \& Clore, G. M. Sequence-specific determination of protein and peptide concentrations by absorbance at $205 \mathrm{~nm}$. Protein Sci. 22, 851-858 (2013).

57. Otwinowski, Z. \& Minor, W. Macromolecular Crystallography, part A Vol. 276 (Academic Press, 1997)

58. Vagin, A. \& Teplyakov, A. Molecular replacement with MOLREP. Acta Crystallogr. Sect. D Biol. Crystallogr. 66, 22-25 (2010).

59. Adams, P. D. et al. PHENIX: A comprehensive Python-based system for macromolecular structure solution. Acta Crystallogr. Sect. D Biol. Crystallogr. 66, 213-221 (2010).

60. Emsley, P. \& Cowtan, K. Coot: Model-building tools for molecular graphics. Acta Crystallogr. Sect. D Biol. Crystallogr. 60, 2126-2132 (2004).

61. Fonseca Guerra, C., van der Wijst, T., Poater, J., Swart, M. \& Bickelhaupt, F. M. Adenine versus guanine quartets in aqueous solution: dispersion-corrected DFT study on the differences in $\pi$-stacking and hydrogen-bonding behavior. Theor. Chem. Acc. 125, 245-252 (2010).

62. van der Wijst, T., Fonseca Guerra, C., Swart, M., Bickelhaupt, F. M. \& Lippert, B. A ditopic ion-pair receptor based on stacked nucleobase quartets. Angew. Chem. Int. Ed. 48, 3285-3287 (2009).

63. Padial, J. S., de Gelder, R., Fonseca Guerra, C., Bickelhaupt, F. M. \& Mecinović, J. Stabilisation of 2,6-diarylpyridinium cation by through-space polar- $\pi$ interactions. Chem. Eur. J. 20, 6268-6271 (2014).

64. Baerends, E. J., Gritsenko, O. V. \& van Meer, R. The Kohn-Sham gap, the fundamental gap and the optical gap: the physical meaning of occupied and virtual Kohn-Sham orbital energies. Phys. Chem. Chem. Phys. 15, 16408-16425 (2013). 
65. Abel, R., Young, T., Farid, R., Berne, B. J. \& Friesner, R. A. Role of the active-site solvent in the thermodynamics of factor Xa ligand binding. J. Am. Chem. Soc. 130, 2817-2831 (2008).

66. Maestro-desmond interoperability tools, version 4.1 (Schrödinger, New York, NY, USA, 2015).

67. Desmond molecular dynamics system, version 4.1 (D. E. Shaw Research, New York, NY, USA, 2015).

68. OPLS2.1. (Schrodinger Inc.; New York, NY, USA, 2015).

69. Wang, L. et al. Accurate and reliable prediction of relative ligand binding potency in prospective drug discovery by way of a modern free-energy calculation protocol and force field. J. Am. Chem. Soc. 137, 2695-2703 (2015).

\section{Acknowledgements}

We thank the Netherlands Research School for Chemical Biology (J.M.), the National Natural Science Foundation of China program 31270763 and The Major State Basic Research Development Program in China 2015CB910503 (H.L.), and the Netherlands Organization for Scientific Research (NWO-ALW, NWO-CW and NWO-EW, F.M.B.) for financial support. The SGC is a registered charity (number 1097737) that receives funds from AbbVie, Boehringer Ingelheim, the Canada Foundation for Innovation, the Canadian Institutes for Health Research, Genome Canada through the Ontario Genomics Institute (OGI-055), GlaxoSmithKline, Janssen, Lilly Canada, the Novartis Research Foundation, the Ontario Ministry of Economic Development and Innovation, Pfizer, Takeda and the Wellcome Trust (092809/Z/10/Z to J.Min). We thank W. Tempel for the data collection of SGF29 and the staff members at beamlines BL17U of the Shanghai Synchrotron Radiation Facility for their assistance in data collection of JARID1A and TAF3.

\section{Author contributions}

J.M. conceived and supervised the project. J.J.A.G.K. synthesized Fmoc-Cme3 and prepared histone peptides. J.J.A.G.K. and J.M. carried out thermodynamic studies and analysed the data. J.H. and H.L. performed structural experiments with JARID1A and TAF3. J.P. and F.M.B. carried out quantum-chemical analyses. C.X., A.D. and J.Min. performed structural experiments with SGF29. B.J.G.E.P. expressed and purified proteins for thermodynamic analyses. W.S. and T.B. carried out WaterMap calculations and analysed the results. J.M. wrote the manuscript with contributions from W.S., T.B., F.M.B. and H.L. All authors contributed in editing the manuscript.

\section{Additional information}

Accession codes: Coordinates of JARID1A PHD-H3(1-10)C4me3, TAF3

PHD-H3(1-10)C4me3 and SGF29 tandem tudor-H3(1-10)C4me3 complexes have been deposited into Protein Data Bank under accession codes 5C11, 5C13 and 5C0M, respectively.

Supplementary Information accompanies this paper at http://www.nature.com/ naturecommunications

Competing financial interests: The authors declare no competing financial interests.

Reprints and permission information is available online at http://npg.nature.com/ reprintsandpermissions/

How to cite this article: Kamps, J. A. G. et al. Chemical basis for the recognition of trimethyllysine by epigenetic reader proteins. Nat. Commun. 6:8911 doi: 10.1038/ncomms9911 (2015).

(c) (i) This work is licensed under a Creative Commons Attribution 4.0 International License. The images or other third party material in this article are included in the article's Creative Commons license, unless indicated otherwise in the credit line; if the material is not included under the Creative Commons license, users will need to obtain permission from the license holder to reproduce the material. To view a copy of this license, visit http://creativecommons.org/licenses/by/4.0/ 